\title{
Frictional slip weakening and shear-enhanced crystallinity in simulated coal fault gouges at slow slip rates
}

\author{
Caiyuan Fan ${ }^{1}$, Jinfeng Liu ${ }^{1,2,3}$, Luuk B. Hunfeld ${ }^{4}$, and Christopher J. Spiers ${ }^{4}$ \\ ${ }^{1}$ School of Earth Sciences and Engineering, Sun Yat-Sen University, Guangzhou, 510275, China \\ ${ }^{2}$ Guangdong Provincial Key Lab of Geodynamics and Geohazards, Sun Yat-Sen University, Zhuhai, 519082, China \\ ${ }^{3}$ Southern Marine Science and Engineering Guangdong Laboratory, Zhuhai, 519082, China \\ ${ }^{4}$ Department of Earth Sciences, Utrecht University, Utrecht, 3584 CB, the Netherlands
}

Correspondence: Jinfeng Liu (liujinf5@mail.sysu.edu.cn)

Received: 31 March 2020 - Discussion started: 9 April 2020

Revised: 20 June 2020 - Accepted: 26 June 2020 - Published: 26 July 2020

\begin{abstract}
Previous studies show that organic-rich fault patches may play an important role in promoting unstable fault slip. However, the frictional properties of rock materials with nearly $100 \%$ organic content, e.g., coal, and the controlling microscale mechanisms remain unclear. Here, we report seven velocity stepping (VS) experiments and one slidehold-slide (SHS) friction experiment performed on simulated fault gouges prepared from bituminous coal collected from the upper Silesian Basin of Poland. These experiments were performed at $25-45 \mathrm{MPa}$ effective normal stress and $100^{\circ} \mathrm{C}$, employing sliding velocities of $0.1-100 \mu \mathrm{m} \mathrm{s}^{-1}$ and using a conventional triaxial apparatus plus direct shear assembly. All samples showed marked slip-weakening behavior at shear displacements beyond $\sim 1-2 \mathrm{~mm}$, from a peak friction coefficient approaching $\sim 0.5$ to (nearly) steadystate values of $\sim 0.3$, regardless of effective normal stress or whether vacuum-dry or flooded with distilled (DI) water at $15 \mathrm{MPa}$ pore fluid pressure. Analysis of both unsheared and sheared samples by means of microstructural observation, micro-area X-ray diffraction (XRD) and Raman spectroscopy suggests that the marked slip-weakening behavior can be attributed to the development of R-, B- and Y-shear bands, with internal shear-enhanced coal crystallinity development. The SHS experiment performed showed a transient peak healing (restrengthening) effect that increased with the logarithm of hold time at a linearized rate of $\sim 0.006$. We also determined the rate dependence of steady-state friction for all VS samples using a full rate and state friction approach. This showed a transition from velocity strengthening to velocity weakening at slip velocities $>1 \mu \mathrm{m} \mathrm{s}^{-1}$ in the
\end{abstract}

coal sample under vacuum-dry conditions but at $>10 \mu \mathrm{m} \mathrm{s}^{-1}$ in coal samples exposed to DI water at $15 \mathrm{MPa}$ pore pressure. The observed behavior may be controlled by competition between dilatant granular flow and compaction enhanced by the presence of water. Together with our previous work on the frictional properties of coal-shale mixtures, our results imply that the presence of a weak, coal-dominated patch on faults that cut or smear out coal seams may promote unstable, seismogenic slip behavior, though the importance of this in enhancing either induced or natural seismicity depends on local conditions.

\section{Introduction}

Carbonaceous materials (e.g., amorphous carbon, graphite, organic matter) are widely present in the lithosphere, including in several large fault zones over the world (Kaneki and Hirono, 2019), such as the Longmenshan thrust belt in China (Kuo et al., 2014), the Atotsugawa fault zone in Japan (Oohashi et al., 2012) and the Alpine fault zone (Kirilova et al., 2017). As is well known, graphite has very low frictional strength and amorphous carbon or organic matter can be transformed into graphite at a seismic slip due to the socalled graphitization process. The presence of carbonaceous materials may therefore act as a lubricant to play a key role in frictional properties and accordingly in promoting the instability of the fault (Oohashi et al., 2011, 2013; Kuo et al., 2014). Meanwhile, organic-rich rocks (such as coal, shale and clay), as main source rocks for (un)conventional natu- 
ral gas, may also play a role in induced seismicity upon gas production (e.g., Kohli and Zoback, 2013; Liu et al., 2020), water injection (e.g., Ellsworth, 2013) and coal mining (e.g., Westbrook et al., 1980). Compared to graphite (Ruan and Bhushan, 1994; Moore and Lockner, 2004; Kirilova et al., 2018), however, limited experimental data on the frictional properties of organic-rich rocks (Liu et al., 2020), particularly coal, under in situ pressure and temperature (PT) conditions are reported. Although coal has been widely investigated because of its importance in fuel energy and industry (Guo et al., 2018; Chen et al., 2019), its frictional properties are not yet well determined and understood. This contribution addresses the frictional properties of coal and the likely mechanisms.

We first focus on coal structure and the graphitization process seen in experiments. Many techniques, such as transmission electron microscopy (TEM), nuclear magnetic resonance (NMR), X-ray diffraction (XRD), Raman spectroscopy and Fourier transform infrared spectroscopy (FTIR), have been applied to determine coal structure because of its complexity and heterogeneity (K. Li et al., 2015; Z. Li et al., 2015; Baysal et al., 2016; Song et al., 2019). From a chemical point of view, coal, in general, mainly consists of aromatic layers wherein aromatic nuclei are surrounded by peripheral aliphatic chains and oxygen functional groups (Mathews and Chaffee, 2012; Ahamed et al., 2019). Lu et al. (2001), based on XRD analysis of Australian coals ranging in rank from high-volatile bituminous to semi-anthracite, proposed a simplified model for describing coal molecular structure. This model suggests that coal consists of both amorphous (nonaromatic structures) and crystalline (condensed, layered aromatic structure) forms of carbon. The aromatic layers in coal may be straightened closer to a more uniform packing during deformation to form graphite under experimental conditions at a constant high confining pressure of $500 \mathrm{MPa}$ and variable temperatures of $300-600^{\circ} \mathrm{C}$, employing strain rates of $\sim 10^{-4}-10^{-6} \mathrm{~s}^{-1}$, to $33 \%$ strains (Ross and Bustin, 1990; Ross et al., 1991). Ross and Bustin (1990) and Ross et al. (1991), based on their experiments, reported that the shear strains associated with strain energy can drastically lower the activation energy and accordingly facilitate the graphitization process. Similarly, molecular dynamics simulations of sliding at the interface between amorphous carbon and diamond films at a rate of $10 \mathrm{~m} \mathrm{~s}^{-1}$, performed by Ma et al. (2014), show that covalent bond reorientation, phase transformation and structural ordering preferentially occur in localized bands in amorphous carbon film and that this shear localization causes weakening. Apart from high-pressure and high-temperature experiments, the graphitization process has also been seen in highvelocity friction experiments. Oohashi et al. (2011), for example, performed friction experiments on both amorphous carbon and graphite using a rotary shear apparatus under conditions of normal stress at $0.5-2.8 \mathrm{MPa}$ and slip rates of $50 \mu \mathrm{m} \mathrm{s}^{-1}-1.3 \mathrm{~m} \mathrm{~s}^{-1}$ in atmospheres of air and nitrogen.
Their experiments showed (a) a steady-state friction coefficient of 0.54 for amorphous carbon at slow slip rates versus 0.1 for graphite at all slip rates, (b) major slip weakening of the amorphous phase at slip rates $>10 \mathrm{~mm} \mathrm{~s}^{-1}$ to a steady-state $\mu$ value of 0.1 , and (c) XRD and TEM evidence of graphitization of the amorphous carbon during shear at high slip rates. The authors suggested that large shear strains, short-lived flash heating and/or stress concentrations at asperity contact points may cause graphitization of amorphous carbon, even at low temperatures and pressures under anoxic environments. Similar friction experiments, performed by Kuo et al. (2014) on natural samples collected from the 2018 Wenchuan earthquake slip zone, also showed graphitization of carbonaceous minerals due to frictional heating at seismic slip rates. On the other hand, Kirilova et al. (2018) performed double direct shear experiments on dry synthetic graphitic carbon at slow slip rates of $1-100 \mu \mathrm{m} \mathrm{s}^{-1}$ and normal stresses of 5 and $25 \mathrm{MPa}$ at room temperature. They found slip weakening of the samples from a peak frictional strength of $\sim 0.4-0.55$ to a steady-state value of $\sim 0.15-0.25$, which is higher than the steady-state $\mu$ value seen in highvelocity friction experiments on graphite. Their TEM and Raman observations suggest shear-enhanced structural disorder with increasing shear strain developing in localized slip zones. In addition, Ruan and Bhushan (1994) investigated the frictional properties of highly oriented pyrolytic graphite using a friction force microscope and TEM and found that the friction coefficient of the well-ordered carbon of the 0001 plane is much smaller compared with that of the randomly ordered carbon. This indicates that internal carbon crystal structural difference may lead to a significant difference in the frictional strength of graphite materials.

We now return to the frictional properties of coal. O'Hara et al. (2006) performed high-velocity $\left(1 \mathrm{~m} \mathrm{~s}^{-1}\right)$ friction experiments on high-volatile bituminous coal at a normal stress of $\sim 0.6 \mathrm{MPa}$, employing a large displacement (maximum of $\sim 80 \mathrm{~m}$ ). Their results demonstrated significant slipweakening behavior and enhanced coal maturity. Specifically, the friction coefficient decreased from $0.8-1.2$ to $0.1-$ 0.4 , and random vitrinite reflectance increased from $\sim 0.6 \%$ to $\sim 0.8 \%$. Besides the thermal effect of shear heating, they suggested that coal gasification, as well as fluctuations in fluid pressure and gas pressurization, also played a role in determining the frictional behavior. Similar coal maturity evolution caused by frictional heating was also reported by Kitamura et al. (2012). More recent research reported by Kaneki and Hirono (2019) investigated the frictional strength of lignite, bituminous coal, anthracite and graphite by performing high-velocity $\left(1 \mathrm{~m} \mathrm{~s}^{-1}\right)$ rotary-shear friction experiments at room temperature. They found that the peak frictional strength for all samples decreased with increasing maturity from 0.5 to 0.2 , and marked dynamic weakening was observed for lignite, bituminous coal and anthracite from peak friction coefficient values of $\sim 0.3-0.5$ to dynamic values of $\sim 0.1-0.2$. TEM, IR and Raman observations per- 
formed on the samples before and after frictional shearing suggested that the marked dynamic weakening behavior observed in lignite, bituminous coal and anthracite was caused by a shear-induced graphitization process, possibly dominated by flash heating (Kaneki and Hirono, 2019). Somewhat different results were obtained by Fan and Liu (2019). These authors performed low-velocity direct shear-friction experiments on precut coal samples (low-volatile bituminous coal) exposed to various fluids (helium, carbon dioxide, water and moisturized methane) at a constant effective normal stress of $2 \mathrm{MPa}$, employing shear rates of $1-10 \mu \mathrm{m} \mathrm{s}^{-1}$. Their results showed (a) no slip weakening, (b) a steady-state friction coefficient for samples exposed to water and moisturized methane of $\sim 0.15$, (c) a much higher friction coefficient in samples exposed to helium $(\sim 0.53)$ and carbon dioxide $(\sim 0.43)$, and velocity-strengthening behavior, regardless of the fluids. Conversely, we performed low-velocity (i.e., $0.1-100 \mu \mathrm{m} \mathrm{s}^{-1}$ ) direct shear experiments to investigate the frictional properties of simulated fault gouges prepared from coal-shale mixtures under (nearly) in situ PT conditions (i.e., effective normal stress of $40 \mathrm{MPa}$ and $100^{\circ} \mathrm{C}$ ) (Liu et al., 2020). We found that only the samples with a coal volume fraction $\geq 50 \%$, including pure coal, showed marked slip-weakening behavior from the peak value of $\sim 0.47$ to a (nearly) steady-state value of $\sim 0.30$, regardless of the employed experimental conditions. Interestingly, such slip weakening is limited to small initial displacements $(2-3 \mathrm{~mm})$ and does not occur during slip reactivation. We, based on the limited microstructure observations, inferred that this slip weakening was caused by strain localization in coalrich shear bands, accompanied by a change in coal molecular structure, as opposed to the graphitization effects seen in high-velocity friction experiments. As the main aim of our recent research (Liu et al., 2020) was to investigate the effects of coal content on the frictional properties of Carboniferous shale in the context of induced seismicity in Carboniferous source rocks below Europe's largest gas field, we only reported one velocity stepping friction experiment on pure coal. As a result, more experimental research is needed to better understand the frictional properties (such as frictional strength, rate-dependent friction and frictional healing) of coal, sheared at slow slip rates under in situ PT conditions, accompanied by the development of coal molecular structure upon shear deformation.

In this paper, we investigate the frictional behavior of deep natural coal (as a source rock for (un)conventional natural gas) under nearly in situ conditions. This was achieved by performing friction experiments on simulated fault gouges prepared from bituminous coal collected from the upper Silesian Basin of Poland. We performed velocity stepping and slide-hold-slide experiments under both vacuum-dry and wet conditions at a constant temperature of $100^{\circ} \mathrm{C}$, employing sliding velocities of $0.1-100 \mu \mathrm{m} \mathrm{s}^{-1}$ and effective normal stresses ranging from 25 to $45 \mathrm{MPa}$. Data on the frictional strength and rate dependence of friction are documented, and a full rate and state friction (RSF) description is derived. In an attempt to understand the likely mechanisms determining frictional behavior, posttest analysis was performed on both unsheared and sheared samples using microstructural observation, micro-area X-ray diffraction and Raman spectroscopy. Data on crystal structure parameters and Raman parameters are also obtained. Finally, we discuss the implications of our findings for understanding the frictional strength and seismic potential of coal-rich faults.

\section{Experimental methods}

\subsection{Approach}

Following Hunfeld et al. (2017) and Liu et al. (2020), we performed direct shear experiments to measure the frictional sliding strength and rate-dependent friction of simulated coal fault gouges at nearly in situ PT conditions for deep coal seams. We apply the rate and state friction (RSF) approach to determine the rate dependence of friction. Posttest analyses by means of microstructural observation, micro-area XRD and Raman spectroscopy were performed on the deformed gouge samples in an attempt to understand the observed frictional behavior.

\subsection{Sample materials}

The coal samples used in this study were prepared from natural high-volatile bituminous coal, with total organic carbon (TOC) of $69.6 \mathrm{wt} \%$, collected from the Brzeszcze Mine (Seam 364) in the upper Silesian Basin of Poland (Hol et al., 2011; Liu et al., 2020). Petrological and chemical analyses reported by Hol et al. (2011) showed that the bituminous coal has a vitrinite reflectance of $0.77 \pm 0.05 \%$ and has a vitrinite content of $60.1 \mathrm{wt} \%$, alongside liptinite at $9.8 \mathrm{wt} \%$ and inertinite at $30.1 \mathrm{wt} \%$. Furthermore, it contains $74.1 \mathrm{wt} \%$ carbon, $5.3 \mathrm{wt} \%$ hydrogen, $1.4 \mathrm{wt} \%$ nitrogen, $0.7 \mathrm{wt} \%$ sulfur, $18.5 \mathrm{wt} \%$ oxygen, $2.9 \mathrm{wt} \%$ moisture and $5.2 \mathrm{wt} \%$ ash (mineral) content. The raw coal sample was crushed to obtain powder with a grain size of $<50 \mu \mathrm{m}$. For each experiment, a gouge layer with a thickness of $\sim 1 \mathrm{~mm}$ (see details in Table 1) was prepared by compacting coal powders in a purpose-made die at $\sim 20 \mathrm{MPa}$ for $\sim 2 \mathrm{~min}$. The gouge layer was then assembled into a "direct shear" assembly, comprising two opposing L-shaped pistons designed for direct shear testing in a triaxial deformation apparatus (following Samuelson and Spiers, 2012). Note that we marked starting, loose coal powders and one coal gouge sample without shear deformation as $\mathrm{S}^{*}$ and $\mathrm{S} 0$, respectively (see Table 1). They are used as the control samples for XRD and Raman tests in an attempt to determine the effects of the shear-friction processes on the molecular structure of carbon in coal. Note that gouge sample $\mathrm{S} 0$ was prepared by compacting at $\sim 20 \mathrm{MPa}$ for $\sim 15 \mathrm{~h}$ at $100^{\circ} \mathrm{C}$. 
Table 1. List of experiments, experimental conditions and key mechanical data. VS: velocity stepping, SHS: slide-hold-slide. Note that all experiments reported here were performed at $\sim 100^{\circ} \mathrm{C} . \sigma_{\mathrm{n}}$ and $P_{\mathrm{f}}$ represent the confining pressures and pore fluid pressure employed in the experiments. $\mu_{\text {peak }}$ represents the peak friction coefficient obtained at $0.5-0.75 \mathrm{~mm}$ of shear displacement, and $\mu_{\mathrm{ss} 1}$ and $\mu_{\mathrm{ss} 2}$ represent the near-steady-state friction coefficient obtained at $\sim 2.2$ and $\sim 5.7 \mathrm{~mm}$ of shear displacement, respectively. $D_{\text {tot }}$ represents the total shear displacement. $t_{0}$ and $t$ represent the thickness of the gouge layer measured before and after the experiments, respectively. $\tau_{\mathrm{ss} 2}$ and $\varepsilon$ represent the steady-state shear stress and shear strain measured at the shear displacement of $\sim 5.7 \mathrm{~mm}$, and the latter is defined as engineering shear strain, i.e., $\varepsilon=d / t_{0}$, where $d$ is the shear displacement. Here, $\varepsilon$ equals 5.7 divided by initial thickness $t_{0}$.

\begin{tabular}{|c|c|c|c|c|c|c|c|c|c|c|c|}
\hline Exp. and sam. & $\begin{array}{r}\sigma_{\mathrm{n}} \\
(\mathrm{MPa})\end{array}$ & $\begin{array}{r}P_{\mathrm{f}} \\
(\mathrm{MPa})\end{array}$ & $\begin{array}{r}\mu_{\text {peak }} \\
(-)\end{array}$ & $\begin{array}{r}\mu_{\mathrm{ss} 1} \\
(-)\end{array}$ & $\begin{array}{r}\mu_{\mathrm{ss} 2} \\
(-)\end{array}$ & $\begin{array}{r}D_{\text {tot }} \\
(\mathrm{mm})\end{array}$ & $\begin{array}{r}V \\
\left(\mu \mathrm{ms}^{-1}\right)\end{array}$ & $\begin{array}{r}t_{0} \\
(\mathrm{~mm})\end{array}$ & $\begin{array}{r}t \\
(\mathrm{~mm})\end{array}$ & $\begin{array}{r}\tau_{\mathrm{ss} 2} \\
(\mathrm{MPa})\end{array}$ & $\begin{array}{r}\varepsilon \\
(-)\end{array}$ \\
\hline $\mathrm{S}^{*}$ & $*$ & $*$ & & & & & & & & & \\
\hline S0 & 20 & * & & & & & & & & & \\
\hline \multicolumn{12}{|l|}{ VS } \\
\hline S1 & 40 & 0 & 0.494 & 0.327 & 0.295 & 6.201 & $0.1-100$ & 1.03 & 0.93 & 11.73 & 5.56 \\
\hline $\mathrm{S} 2$ & 40 & 0 & 0.465 & 0.278 & 0.244 & 5.563 & $0.1-100$ & 0.92 & 0.75 & 9.62 & 6.16 \\
\hline S3 & 40 & 15 & 0.524 & 0.338 & 0.282 & 5.602 & $0.1-100$ & 1.00 & 0.75 & 6.87 & 5.70 \\
\hline S4 & 50 & 15 & NA & 0.279 & 0.253 & 6.183 & $0.1-100$ & 1.18 & 0.83 & 8.78 & 4.85 \\
\hline S5 & 55 & 15 & 0.441 & 0.258 & 0.228 & 5.766 & $0.1-100$ & 0.90 & 0.65 & 8.91 & 6.33 \\
\hline S6 & 55 & 15 & 0.485 & 0.293 & 0.256 & 6.010 & $0.1-100$ & 0.90 & 0.73 & 10.14 & 6.33 \\
\hline S7 & 60 & 15 & 0.454 & 0.273 & 0.245 & 5.750 & $0.1-100$ & 1.00 & 0.80 & 10.85 & 5.70 \\
\hline \multicolumn{12}{|l|}{ SHS } \\
\hline S8 & 55 & 15 & 0.460 & 0.275 & 0.244 & 6.057 & 1 & 1.00 & 0.80 & 9.64 & 5.70 \\
\hline
\end{tabular}

$\mathrm{S}^{*}$ represents the starting, loose coal powders without the pre-compaction process. S0 represents the compacted coal gouge layer only, i.e., without the shear deformation. $\mathrm{S}^{*}$ and S0 are used as the control samples for XRD and Raman tests in an attempt to determine the effects of shear deformation on the molecular structure of carbon in coal. NA: this value is missing.

\subsection{Direct shear experiments and posttest sample treatment}

We performed eight direct shear experiments at a constant temperature of $100^{\circ} \mathrm{C}$ using a conventional triaxial testing machine (referred to as the Shuttle Machine; see Verberne et al., 2014a) equipped with the direct shear assembly described above. An independent ISCO 65 volumetric (syringe) pump was used to control pore fluid pressure. A detailed description of the machine was given by Verberne et al. (2014a) and Hunfeld et al. (2017). The experiments employed confining pressures $\left(\sigma_{\mathrm{n}}\right)$ of $40,50,55$ and $60 \mathrm{MPa}$, as well as a constant pore fluid pressure of $P_{\mathrm{f}}=15 \mathrm{MPa}$ or under vacuumdry conditions (i.e., $P_{\mathrm{f}}=0$ ). Distilled (DI) water was used as the pore fluid for experiments S3-S8, while experiments $\mathrm{S} 1$ and $\mathrm{S} 2$ were tested under vacuum-dry conditions (see Table 1 for details of the experimental conditions). In each experiment, the sample assembly, initially drained to the lab air, was first heated to $\sim 100^{\circ} \mathrm{C}$ at a confining pressure of $\sim 20 \mathrm{MPa}$ and left to equilibrate for $\sim 15 \mathrm{~h}$ (overnight). Then the pore fluid was introduced into the sample and pressurized to $15 \mathrm{MPa}$ at a confining pressure of $\sim 20 \mathrm{MPa}$. The confining pressure was subsequently increased to a certain value and left in the system for $\sim 3 \mathrm{~h}$ to equilibrate before shearing. Seven velocity stepping (VS) experiments and one slide-hold-slide (SHS) experiment were conducted in this study (see Table 1). In the VS experiments, samples were sheared at a constant velocity $(V)$ of $1 \mu \mathrm{m} \mathrm{s}^{-1}$ for $\sim 2.5 \mathrm{~mm}$ of shear displacement, after which the loading rate was instantaneously stepped in the range $0.1-100 \mu \mathrm{m} \mathrm{s}^{-1}$ over total displacement up to almost $6 \mathrm{~mm}$. The SHS experiment was also performed at a constant velocity $(V)$ of $1 \mu \mathrm{m} \mathrm{s}^{-1}$ interrupted by hold intervals in the range 300 to $30000 \mathrm{~s}$ in an attempt to determine the healing effects of coal.

After each experiment, the direct shear setup was dismantled, and intact fragments of the sheared gouge layers were recovered and oven-dried for several days. Note that, for the observation using a scanning electron microscope (SEM), to avoid the potential problem caused by the use of carbonbearing epoxy, no special treatment was performed on the samples. The microstructure of the sheared samples S1-S8 was observed using an optical microscope and an SEM. For each sample, we carefully chose the fragments that have a clear, clean slip surface and the fragments that have a relatively flat cross section in an orientation parallel to the shear direction and perpendicular to the shear plane (e.g., Fig. 1a). Note that artificial microfractures formed during extraction of the samples from the experimental apparatus and subsequent treatment can be easily recognized and excluded. Micro-area XRD and Raman spectroscopy analyses were performed on the principal slip zone (PSZ) and weakly deformed zone (WDZ; terminology following Oohashi et al., 2011) of samples S1-S8 (e.g., Fig. 1c). Note that the surface of WDZ in Fig. 1c was exposed by scraping the PSZ using 
abrasive paper. Recall that samples $\mathrm{S}^{*}$ and S0 (i.e., without shear deformation), as control experiments, were also tested using XRD and Raman spectroscopy. The location of the micro-area was selected randomly in the PSZ, WDZ or unsheared surface and was schematically marked in Fig. $1 \mathrm{~b}$ and c (blue circles).

\subsection{Posttest analysis}

\subsubsection{Microstructural methods}

A Leica EZ4w optical stereomicroscope and a tabletop SEM fitted with an energy disperse spectroscope (EDS) were used to investigate the microstructure of the fragments retrieved from the deformed samples. Note that the fragments were not coated because coal samples have sufficient electroconductivity. The samples were imaged in the secondary electron mode using an acceleration voltage of $15-20 \mathrm{kV}$. In addition, an EDS was used to determine whether the observed grains are coal components or other minerals.

\subsubsection{Micro-area XRD}

We performed the micro-area XRD experiments on samples S0-S8 (except S2 and S6) in an attempt to determine the crystal structure of coal samples. Sample $S^{*}$ was tested by $\mathrm{X}$-ray powder diffraction in a conventional mode. This was achieved using the SmartLab $9 \mathrm{~kW}$ X-ray diffractometer with a $\mathrm{Cu}$ target at ambient temperature. Samples were scanned in the $2 \theta$ range from 10 to $65^{\circ}$ at a rate of $1^{\circ} \mathrm{min}^{-1}$. The micro-area ( $\sim 300 \mu \mathrm{m}$ in diameter) in the PSZ and WDZ was measured for each sheared sample (see Fig. 1c). Note that samples $\mathrm{S}^{*}$, S0 and S5 were measured twice for data reproducibility. For those samples, we took the average values as the parameters and the standard deviations as error bars.

\subsubsection{Raman spectroscopy}

We performed Raman measurements on samples $\mathrm{S}^{*}-\mathrm{S} 8$ to determine the development of coal maturity upon the shearfriction experiments. This was done using a Renishaw in$\mathrm{Via}^{\mathrm{TM}}$ laser Raman instrument (with a spectral resolution of $1 \mathrm{~cm}^{-1}$ ) that was connected to a Leica DMLM microscope. The $514.5 \mathrm{~nm}$ argon-ion green laser was used for all experiments. The laser was focused through a $\times 50$ objective, with a laser spot size of $\sim 2 \mu \mathrm{m}$. We used a laser power of $0.2-$ $1.0 \mathrm{~mW}$ ( $1 \%-5 \%$ of $\sim 17 \mathrm{~mW}$ full power) to avoid thermal damage on the targeted surface of coal samples. The scan range was limited to $50-3000 \mathrm{~cm}^{-1}$ in order to assess the first-order region $\left(900-2000 \mathrm{~cm}^{-1}\right)$ and part of the secondorder region $\left(2200-3300 \mathrm{~cm}^{-1}\right)$. For each scan, we set the acquisition time at $10 \mathrm{~s}$ for three to five cumulative scans. For the unsheared and sheared samples (S0-S8), we measured three points randomly distributed in the unsheared or principal slip surface for each sample. Note that for sample S4 only, we also measured three points in the weakly deformed zone. We accordingly took the mean values as the representative Raman parameters and the standard deviations as error bars for each sample. Note that we measured only one point in the powdered sample $\mathrm{S}^{*}$.

\subsection{Data acquisition, processing and analysis}

\subsubsection{Mechanical data acquisition and treatment}

Internal axial force, confining pressure, pore fluid pressure, sample temperature and loading piston displacement were measured in each experiment and the signals logged using a 16 bit National Instruments analog-digital (AD) converter and logging system (for details, see Hunfeld et al., 2017). Following Liu et al. (2020) and Hunfeld et al. (2017), the data were processed to yield sample shear stress versus shear displacement data corrected for machine stiffness (see details in Liu and Hunfeld, 2020). The frictional strength of the samples was characterized by defining the apparent coefficient of sliding friction $(\mu)$ as the ratio of sample shear stress $(\tau)$ over the effective normal stress $\left(\sigma_{\mathrm{n}}^{\text {eff }}\right)$, assuming zero cohesion:

$\mu=\frac{\tau}{\sigma_{\mathrm{n}}^{\text {eff }}}$,

where $\sigma_{\mathrm{n}}^{\text {eff }}=\sigma_{\mathrm{n}}-P_{\mathrm{f}}$. Here, $\sigma_{\mathrm{n}}$ represents the normal stress or confining pressure employed in the experiments, and $P_{\mathrm{f}}$ represents the pore fluid pressure.

The rate dependence of friction was quantified using the RSF theory (Dieterich, 1979; Ruina, 1983) coupled with the empirical Dieterich-type "aging law" (e.g., Marone, 1998):

$$
\begin{aligned}
& \mu=\mu_{0}+a \ln \left(\frac{V}{V_{0}}\right)+b \ln \left(\frac{V_{0} \theta}{D_{\mathrm{c}}}\right), \\
& \frac{\mathrm{d} \theta}{\mathrm{d} t}=1-\frac{V \theta}{D_{\mathrm{c}}},
\end{aligned}
$$

which describes the evolution of the friction coefficient $\mu$ from a reference steady-state value $\left(\mu_{0}\right)$ towards a new steady-state value over a critical slip distance $\left(D_{\mathrm{c}}\right)$ in response to an instantaneous change in sliding velocity from an initial sliding velocity $\left(V_{0}\right)$ to a new sliding velocity $(V)$. The state variable $\theta$, which describes the evolution of gouge friction via Eq. (3), is commonly viewed as the average life span of a population of grain-to-grain contacts (Marone, 1998). At steady state, i.e., when $\mathrm{d} \theta / \mathrm{d} t=0$, Eq. (2) is reduced to

$(a-b)=\frac{\mu-\mu_{0}}{\ln \left(V / V_{0}\right)}$,

where the parameter $(a-b)$ reflects the rate sensitivity of the friction coefficient. From an RSF point of view, if fault rocks exhibit an increase in frictional strength upon increased sliding rate, i.e., velocity-strengthening behavior with $(a-b)>$ 0 , they are not prone to generating accelerating slip and are termed conditionally stable (Scholz, 2019). On the other hand, when the frictional strength of a fault rock decreases 

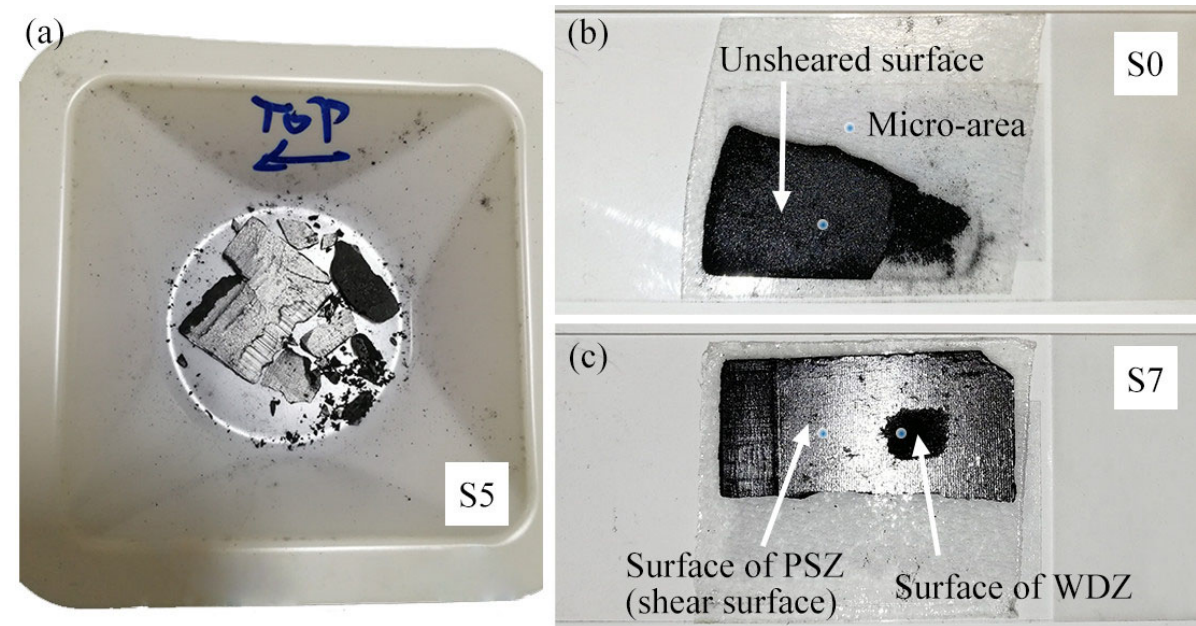

Figure 1. Post-treatment of the recovered fragments used for microstructural observation, XRD and Raman spectroscopy. (a) Stored loose fragments. (b) The free surface of the unsheared sample S0 that was glued on a glass slide. (c) The slip surface of sample S7, showing the surface of the principal slip zone (PSZ) and weakly deformed zone (WDZ).

upon increased sliding rate, the fault rock exhibits velocityweakening behavior with $(a-b)>0$. Given sufficient elastic compliance in the loading system, this behavior can cause repetitive slip instabilities, or stick-slip events, viewed as the laboratory equivalent of earthquakes (Brace and Byerlee, 1966; Marone, 1998; Scholz, 1998). Here, we solve Eq. (2) accompanied by Eq. (3) simultaneously with an equation describing the elastic interaction with the testing machine via the stiffness using Eq. (1) as a constraint. The values for $a, b$ and $D_{\mathrm{c}}$ can then be obtained as the solutions of a nonlinear inverse problem using an iterative least-squares minimization method (Ikari et al., 2009), thereby obtaining a full RSF description of the material from our experiments. In performing RSF inversion, departures from steady-state frictional sliding were corrected using linear detrending of hardening or softening behavior (see Fig. 4a), and thus the slope of linear detrending $(\eta)$ was obtained. A detailed description was also given by Blanpied et al. (1998) and Ikari et al. (2013).

\subsubsection{Determining crystal structure parameters from XRD data}

We first corrected for the background noise of the resulting diffractograms using a spline curve (see Fig. 2), obtaining an approximative profile of crystalline carbon (i.e., the background-subtracted intensity profile shown in Fig. 2). The obtained profile was further deconvoluted using Lorentzian and Gaussian functions to determine the crystal structure parameters of coal. Specifically, Lorentzian peaks were first employed to determine minerals in the $2 \theta$ range of $\sim 16$ $30^{\circ}\left(10-30^{\circ}\right.$ for powdered sample $\left.\mathrm{S}^{*}\right)$ and $\sim 35-58^{\circ}$ in an attempt to remove the mineral peaks from the backgroundsubtracted curve. We then employed three Gaussian peaks to fit the background-subtracted, mineral-free profile at around
20, 26 and $43^{\circ}$, obtaining the $\gamma$ band, 002 band and 10 band, respectively (see Fig. 2). In general, the $\gamma$ band reflects the structure of ring-free saturated hydrocarbons (see detailed description in Yen et al., 1961), whereas the 002 and 10 bands reflect the ring structure of the aromatic layers of crystalline carbon (Lu et al., 2001). The fitting parameters, such as peak position $(\theta)$, full-width at half-maximum $(\beta)$ and area $(A)$, were obtained. The structure parameters of carbon crystallite in coal, such as interlayer spacing $\left(d_{002}\right)$, crystallite stacking height $\left(L_{\mathrm{c}}\right)$ and crystallite diameter $\left(L_{\mathrm{a}}\right)$, were determined using the empirical Bragg and Scherrer equations (Eqs. 57). Note that we took the mean values as the parameter for samples $\mathrm{S}^{*}$, S0 and S5.

$$
\begin{aligned}
& d_{002}=\frac{\lambda}{2 \sin \theta_{002}} \\
& L_{\mathrm{c}}=\frac{0.89 \lambda}{\beta_{002} \cos \theta_{002}} \\
& L_{\mathrm{a}}=\frac{1.84 \lambda}{\beta_{10} \cos \theta_{10}}
\end{aligned}
$$

Here, $\lambda$ is the wavelength of the applied X-ray $(0.154056 \mathrm{~nm}$ for $\mathrm{Cu} \mathrm{K} \alpha$ radiation); $\theta_{002}, \beta_{002}, \theta_{10}$ and $\beta_{10}$ represent the peak position and full-width at half-maximum of bands 002 and 10, respectively. Theoretically, the areas of the bands 002 and $\gamma\left(A_{002}\right.$ and $\left.A_{\gamma}\right)$ are believed to be equal to the number of aromatic and aliphatic carbon atoms, respectively (Yen et al., 1961), so that the aromaticity $\left(f_{\mathrm{a}}\right)$ of the samples can be estimated using Eq. (8). Coal rank can also be assessed using the ratio of the maximum intensity of 002 over that of the $\gamma$ band $\left(I_{002} / I_{\gamma}\right.$, as seen in Eq. 9$)$.

$f_{\mathrm{a}}=\frac{A_{002}}{A_{002}+A_{\gamma}}$ 


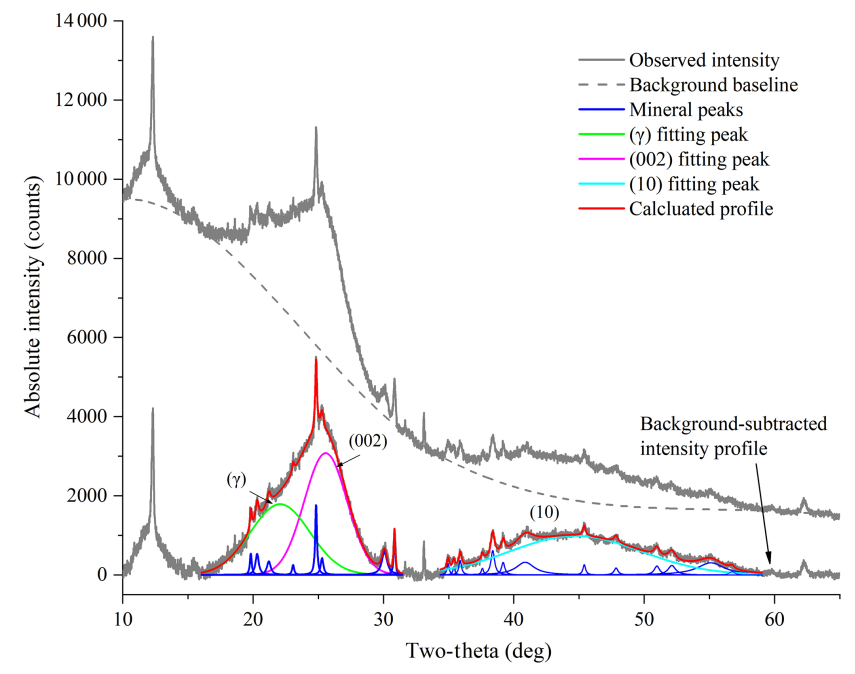

Figure 2. Fitting curves in an X-ray diffraction pattern for sample S1.

Coal rank $=\frac{I_{002}}{I_{\gamma}}$

\subsubsection{Determining Raman parameters}

Raman spectroscopy is a powerful tool for analyzing information on the molecular structure of organic matter (Ulyanova et al., 2014). It is well known that the $\mathrm{G}$ band, which is located around $1580 \mathrm{~cm}^{-1}$ in Raman spectra, is the only peak in the first-order region (i.e., $900-2000 \mathrm{~cm}^{-1}$ ) for a pure single graphite crystal. The D band is another peak located around $1350 \mathrm{~cm}^{-1}$ in Raman spectra, which is generally present along with the $\mathrm{G}$ band for other carbon materials such as graphite with a defective lattice, activated carbon and coal (Tuinstra and Koenig, 1970; Potgieter-Vermaak et al., 2011; Childres et al., 2013). The Raman parameters for coal include the peak position, full-width at half-maximum (FWHM), and intensity of the G and D band, the Raman band separation (RBS: G position minus D position), the intensity ratio of the $\mathrm{D}$ band over the $\mathrm{G}$ band $\left(I_{\mathrm{D}} / I_{\mathrm{G}}\right)$, and the saddle index ( $\mathrm{SI}$ is the intensity of the $\mathrm{G}$ band divided by that of the saddle). These parameters can be obtained by several processing methods (Beyssac et al., 2003; Sadezky et al., 2005; Wilkins et al., 2014; Henry et al., 2018; Khatibi et al., 2018). In this paper, we use the method proposed by Henry et al. (2018) to determine the Raman parameters, as it has been well tested for Carboniferous organic-rich mudstones and coals (Henry et al., 2019). In general, Henry's method includes the following: (a) the raw Raman spectra were first smoothed using a Savitzky-Golay filter, i.e., a 21-point quadratic polynomial algorithm; (b) a third-order polynomial function was then used to correct for baseline; and (c) the smooth, baseline-removed spectra were finally normalized to a common G-band height of 2000 arbitrary units. Specifically, we used the automated Microsoft Excel ${ }^{\circledR}$ spreadsheet proposed by Henry et al. (2018) to process our spectra data obtained at $900-2000 \mathrm{~cm}^{-1}$.

\section{Results}

\subsection{Mechanical data}

\subsubsection{Frictional strength of simulated coal fault gouges}

The typical apparent friction coefficient $(\mu)$ versus displacement data obtained in velocity stepping experiments (Exp. S1-S7) is plotted in Fig. 3. All experiments plotted in Fig. 3a showed rapid, near-linear initial loading up to a peak friction coefficient at a shear displacement of $\sim 0.6 \mathrm{~mm}$, followed by sharp, post-peak slip weakening from peak values of $\sim 0.48$ to a nearly (quasi) steady-state value of $\sim 0.3$ at a shear displacement of $\sim 2.2 \mathrm{~mm}$. The quasi-steady-state friction coefficient decreased slightly with displacement, reaching a new quasi-steady-state value at $4-6 \mathrm{~mm}$. This slight weakening might be caused by the reduction of the loadsupporting area of the sample during shear deformation. Nevertheless, to quantify this effect, we define $\mu_{\text {peak }}$ as the peak friction coefficient obtained at $0.5-0.75 \mathrm{~mm}$ of shear displacement, and we take $\mu_{\mathrm{ss} 1}$ and $\mu_{\mathrm{ss} 2}$ to represent the nearsteady-state friction coefficient values obtained at $\sim 2.2$ and $\sim 5.7 \mathrm{~mm}$ of shear displacement, respectively. These friction coefficient data ( $\mu_{\text {peak }}, \mu_{\mathrm{ss} 1}$ and $\left.\mu_{\mathrm{ss} 2}\right)$ are plotted in Fig. $3 \mathrm{~b}$ as a function of effective normal stress, which indicates that they are more or less independent of effective normal stress. The largest values for $\mu_{\text {peak }}(0.524)$ and $\mu_{\mathrm{ss} 1}(0.338)$ were obtained in experiment S3, which was performed at a confining pressure of $40 \mathrm{MPa}$ and a pore water pressure of $15 \mathrm{MPa}$ (i.e., at effective normal stress of $25 \mathrm{MPa}$ ). The values of $\mu_{\text {peak }}$ and $\mu_{\text {ss } 1}$ obtained at vacuum-dry conditions (i.e., $\mu_{\text {peak }}$ of $\sim 0.48$ and $\mu_{\mathrm{ss} 1}$ of $\sim 0.30$ for experiments S1 and S2) are slightly higher than those $\left(\mu_{\text {peak }}=\sim 0.46\right.$ and $\left.\mu_{\text {ss } 1}=\sim 0.28\right)$ obtained for samples S5 and S6 that were exposed to DI water at the same effective normal stress of $40 \mathrm{MPa}$. All frictional strength data are summarized in Table 1, including $\mu_{\text {peak }}, \mu_{\mathrm{ss} 1}$ and $\mu_{\mathrm{ss} 2}$.

\subsubsection{Rate dependence of friction}

The individual RSF parameters $a, b$ and $D_{\mathrm{c}}$, as well as the rate sensitivity parameter $(a-b)$, obtained in all velocity stepping experiments using a full RSF inversion approach are summarized in Table 2. The slope $\eta$ of the linear slipweakening trend obtained after each upward velocity step in the displacement interval of $2-4 \mathrm{~mm}$ in experiments S1-S7 is also listed in Table 2. The $(a-b)$ data obtained for upward steps are plotted in Fig. $4 \mathrm{~b}$ as a function of effective normal stress. Here we plot upward stepping data only, as it is these that are most relevant to rupture nucleation (Marone, 1998). Almost all $(a-b)$ values fall in the range of -0.006 

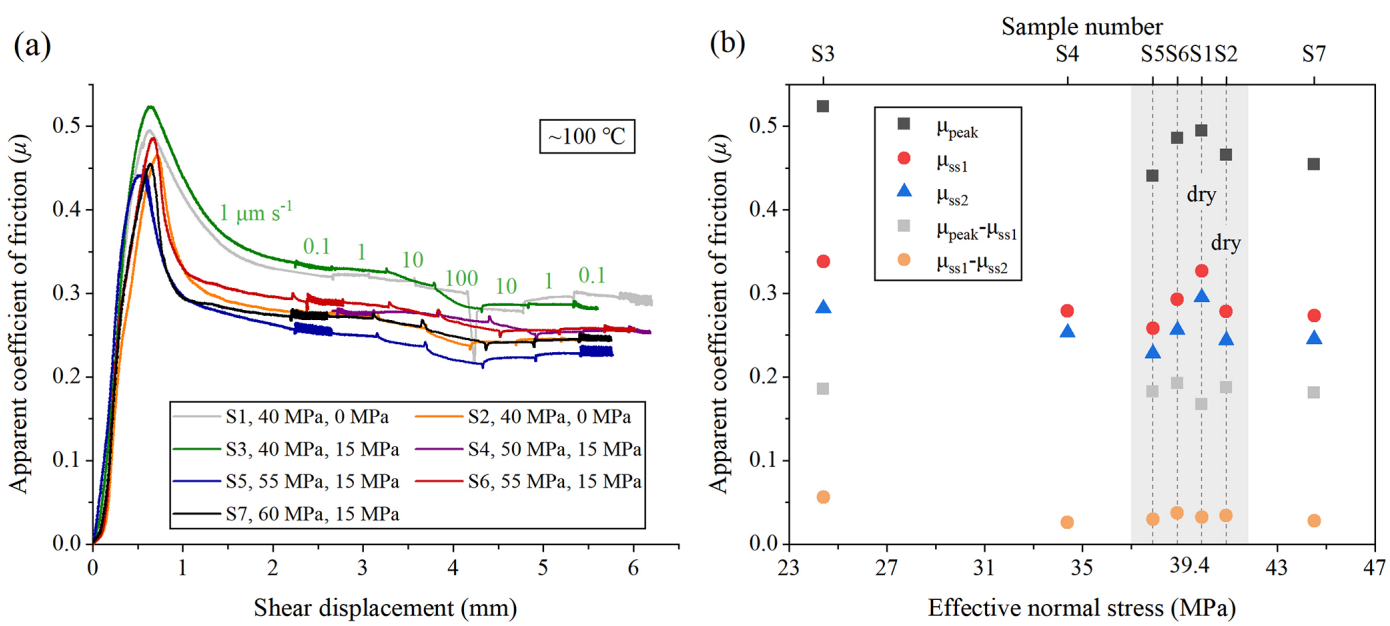

Figure 3. Frictional properties of samples S1-S7 obtained from the velocity stepping experiments. (a) Apparent coefficient of friction ( $\mu$ ) against shear displacement. (b) Apparent coefficient of friction $(\mu)$ against effective normal stress. Note that the data offset is given in the grey area; i.e., the data plotted on the vertical dashed lines were all obtained at $\sim 40 \mathrm{MPa}$ effective normal stress but are horizontally offset here for readability.

to +0.002 and systematically decrease in the higher-velocity steps in all samples (see Fig. 4b). It is also clear from Fig. 4b that $(a-b)$ values are insensitive to effective normal stress but sensitive to velocity and pore fluid condition. Specifically, all samples show velocity strengthening at velocities stepped from 0.1 to $1 \mu \mathrm{m} \mathrm{s}^{-1}$ (where $a-b>0$ ) but velocity weakening in steps from 10 to $100 \mu \mathrm{m} \mathrm{s}^{-1}$ (where $a-b<0$ ). For velocity steps from 1 to $10 \mu \mathrm{m} \mathrm{s}^{-1}$, sample S2 tested under vacuum-dry conditions shows velocity weakening (i.e., $a-b<0$ ), while samples tested with DI pore water at a pressure of $15 \mathrm{MPa}$ show velocity strengthening, except for sample S5, which exhibits velocity weakening.

In addition to the above treatment of the RSF data, the slope $\eta$ of the linear slip-weakening portions of the friction vs. displacement curves is plotted in Fig. $4 \mathrm{c}$ as a function of the up-step velocity. This shows that the absolute magnitude of $\eta$ systematically increases with increasing slip rate, reflecting velocity-enhanced slip-weakening behavior. We note that this type of linear slip-weakening behavior has also been observed in velocity stepping $\left(0.03-100 \mu \mathrm{m} \mathrm{s}^{-1}\right)$ experiments performed on a natural fault gouge (37\%-65\% clay minerals, up to $40 \%$ quartz + plagioclase and little calcite) collected from the Nankai subduction zone in Japan and has been put forward as a mechanism for promoting slow earthquakes (see details in Ikari et al., 2013). This behavior, seen in Fig. 4c, may warrant deeper investigation in the future.

\subsubsection{Frictional healing effects}

The slide-hold-slide loading path data (Exp. S8) shown in Fig. 5a indicate a clear but minor strength recovery or healing effect $(\Delta \mu)$ upon re-shear, followed by slip weakening to achieve a new quasi-steady state. The magnitude of re- strengthening $(\Delta \mu)$ increases with the logarithm of hold time $(t)$ and is well described by the equation $\Delta \mu=\beta \log \left(1+t / t_{c}\right)$ (e.g., Marone, 1998), where $\beta=0.006 \pm 0.001$ and $t_{c}=9 \pm$ 9 s (Fig. 5b).

\subsection{Microstructure of the deformed coal gouge}

The representative microstructure for a sliding surface of sample S6 obtained using an optical microscope in a reflected light mode is shown in Fig. 6a, indicating a highly reflective (mirror-like) area located in the left half of Fig. 6a. This may be similar to the reported mirror slip surface (Siman-Tov et al., 2013; Fondriest et al., 2013; Verberne et al., 2014b). In addition, a principal boundary slip zone (PSZ; 15-25 $\mu \mathrm{m}$ thick) accompanied by a weakly deformed zone (WDZ) was observed in all deformed coal gouges (see Fig. 6b for a representative reflected light micrograph of sample $\mathrm{S} 1$ in an orientation parallel to shear direction). Note that unlike boundary shear bands that were observed in all samples, R- and Y-shear bands were only observed in sample S5 (see Fig. 6c and d). This may be because the surface of the fragments chosen from other samples were not flat enough to capture $\mathrm{R}$ - and Y-shear bands. The SEM secondary electron images shown in Fig. 7a-e may also indicate the development of first microfractures inside the starting coal grains $(\sim 50 \mu \mathrm{m})$, then failure to form small grains $(<10 \mu \mathrm{m})$ and finally shear bands. This likely reflects the process of cataclasis or granular flow during shear deformation in a coal gouge (Niemeijer and Spiers, 2007; Verberne et al., 2014b; Hadizadeh et al., 2015). More importantly, a marked stacked-layer structure was clearly observed at the margin of the PSZ (see Fig. 7f), likely reflecting an interaction between the PSZ and WDZ as well as the role of the PSZ during the friction process. EDS data measured at the three representative spots located 


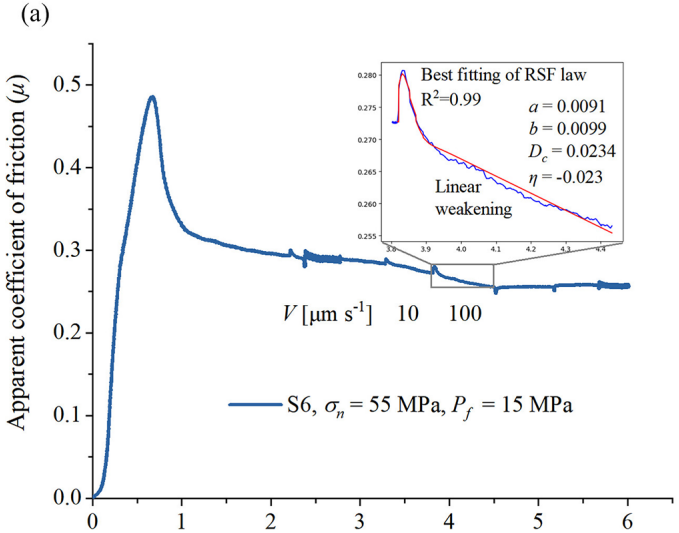

(c)

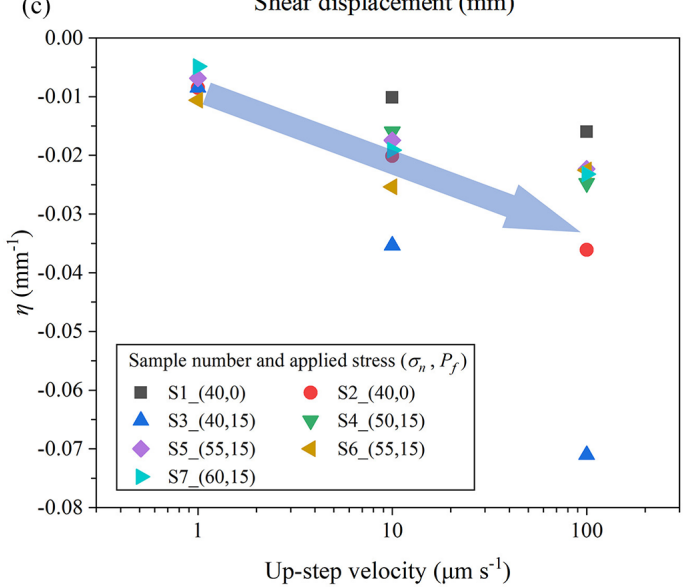

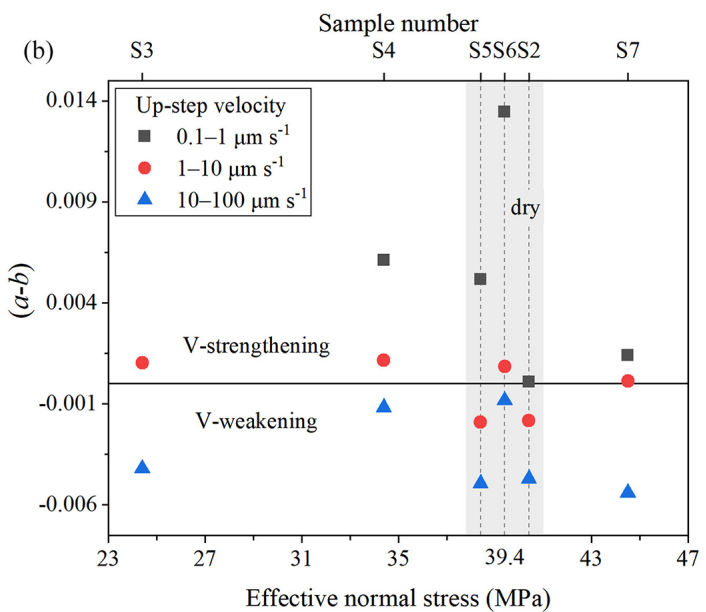

Effective normal stress $(\mathrm{MPa})$

Figure 4. (a) Results of experiment S6, illustrating the best fitting of a full RSF law to the experimental data obtained at the velocity step from 10 to $100 \mathrm{um} \mathrm{s}^{-1}$. (b) Values of $(a-b)$ obtained from upward velocity steps using a full RSF fit versus effective normal stress at a linear scale. Note that the data offset is given in the grey area; i.e., the data plotted on the vertical dashed lines were all obtained at $\sim 40 \mathrm{MPa}$ effective normal stress but are horizontally offset here for readability. (c) The slope $\eta$ of a linear slip-weakening trend versus up-step velocity in velocity stepping.
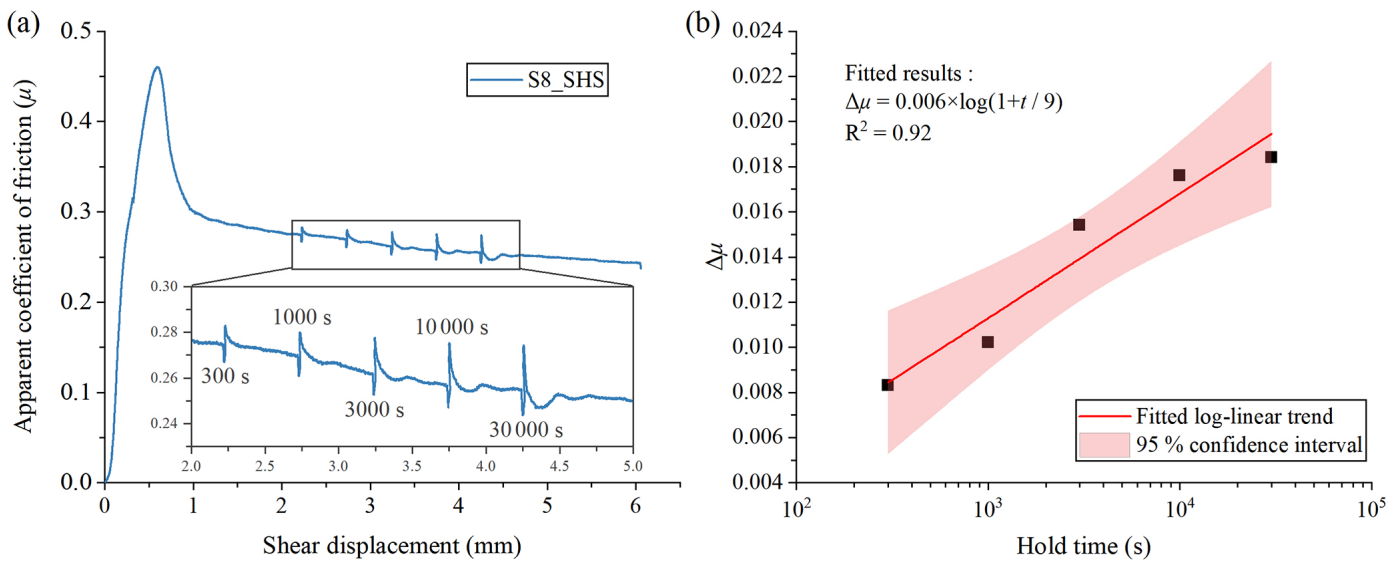

Figure 5. Slide-hold-slide experimental data for sample S8 tested at a pore fluid pressure of $15 \mathrm{MPa}$ and a confining pressure of $55 \mathrm{MPa}$. (a) Friction coefficient versus shear displacement, showing the slide-hold-slide testing sequence. (b) Transient peak healing or post-hold frictional restrengthening plotted as a function of the logarithm of hold time. The black solid squares represent the experimental data derived from (a). 
Table 2. Summary of RSF data for all velocity stepping experiments reported in this paper.

\begin{tabular}{llrrrrrrr}
\hline & Sam. and steps & $\begin{array}{r}V_{0} \\
\left(\mu \mathrm{m} \mathrm{s}^{-1}\right)\end{array}$ & $\begin{array}{r}V \\
\left(\mu \mathrm{m} \mathrm{s}^{-1}\right)\end{array}$ & $\begin{array}{r}a-b \\
(-)\end{array}$ & $\begin{array}{r}a \\
(-)\end{array}$ & $\begin{array}{r}b \\
(-)\end{array}$ & $\begin{array}{r}D_{\mathrm{c}} \\
(\mathrm{mm})\end{array}$ & $\begin{array}{r}\eta \\
\left(\mathrm{mm}^{-1}\right)\end{array}$ \\
\hline S1 & V_step1 & 0.1 & 1 & $\mathrm{NA}$ & $\mathrm{NA}$ & $\mathrm{NA}$ & $\mathrm{NA}$ & -0.010 \\
& V_step2 & 1 & 10 & -0.0055 & 0.0051 & 0.0094 & 0.0074 & $\begin{array}{r}-0.016 \\
\text { N_step3 }\end{array}$ \\
& 10 & 100 & $\mathrm{NA}$ & $\mathrm{NA}$ & $\mathrm{NA}$ & $\mathrm{NA}$ & $\mathrm{NA}$ \\
\hline S2 & V_step1 & 0.1 & 1 & 0.0001 & 0.0030 & 0.0029 & 0.0029 & -0.009 \\
& V_step2 & 1 & 10 & -0.0018 & 0.0028 & 0.0047 & 0.0120 & -0.020 \\
& V_step3 & 10 & 100 & -0.0047 & 0.0629 & 0.0676 & 0.0440 & -0.036 \\
\hline S3 & V_step1 & 0.1 & 1 & $\mathrm{NA}$ & $\mathrm{NA}$ & $\mathrm{NA}$ & $\mathrm{NA}$ & -0.008 \\
& V_step2 & 1 & 10 & 0.0010 & 0.0034 & 0.0024 & 0.0032 & -0.035 \\
& V_step3 & 10 & 100 & -0.0042 & 0.0637 & 0.0679 & 0.0370 & -0.071 \\
\hline S4 & V_step1 & 0.1 & 1 & 0.0061 & 0.0128 & 0.0067 & 0.0014 & NA \\
& V_step2 & 1 & 10 & 0.0012 & 0.0043 & 0.0031 & 0.0101 & -0.016 \\
& V_step3 & 10 & 100 & -0.0012 & 0.3271 & 0.3283 & 0.0578 & -0.025 \\
\hline S5 & V_step1 & 0.1 & 1 & 0.0052 & 0.0327 & 0.0276 & 0.0014 & -0.007 \\
& V_step2 & 1 & 10 & -0.0019 & 0.0057 & 0.0076 & 0.0364 & -0.017 \\
& V_step3 & 10 & 100 & -0.0049 & 0.1008 & 0.1057 & 0.0436 & -0.022 \\
\hline S6 & V_step1 & 0.1 & 1 & 0.0135 & 0.0470 & 0.0336 & 0.0071 & -0.011 \\
& V_step2 & 1 & 10 & 0.0009 & 0.0039 & 0.0030 & 0.0134 & -0.025 \\
& V_step3 & 10 & 100 & -0.0008 & 0.0091 & 0.0099 & 0.0234 & -0.023 \\
\hline S7 & V_step1 & 0.1 & 1 & 0.0014 & 0.0047 & 0.0033 & 0.0067 & -0.005 \\
& V_step2 & 1 & 10 & 0.0001 & 0.0029 & 0.0028 & 0.0143 & -0.019 \\
& V_step3 & 10 & 100 & -0.0054 & 0.4209 & 0.4264 & 0.0586 & -0.023 \\
\hline
\end{tabular}

NA: this value cannot be obtained as the fitting quality is low.

in sample S4 (see Fig. 7b, c and f) are shown in Fig. 7g and indicate high $\mathrm{C}$ and $\mathrm{O}$ but little mineral content in the WDZ and PSZ.

\subsection{Development of coal crystal structure (XRD data)}

Raw X-ray diffractograms of coal samples $\mathrm{S}^{*}-\mathrm{S} 8$ are presented in Fig. 8. Note that the diffractogram for the coal powdered sample $\left(\mathrm{S}^{*}\right)$ was scaled to a comparable size with other samples. Note also that the minor peaks observed in Fig. 8 represent minerals (such as kaolinite and dolomite) in coal samples. Figure 8 shows that the 002, 10 and $\gamma$ side bands generally characteristic of coal were observed in all samples (following Hirsch, 1954, and Lu et al., 2001). In addition, all samples showed a high background intensity, indicating that a significant proportion of amorphous carbon (i.e., nonaromatic component) was present in our coal samples (Dun et al., 2013). This high background is characteristic of materials having nonuniformly developed crystal structures (e.g., coal), regardless of the specimen holder or diffractometer used in the experiments (e.g., K. Li et al., 2015; Baysal et al., 2016). Importantly, Fig. 8 demonstrates an apparent difference between unsheared ( $\mathrm{S}^{*}$ and $\mathrm{S} 0$ ) and sheared (S1-S8) samples compared to the minor difference observed between the sheared samples. This strongly suggests the effects of shear and friction on the development of molecular structure in coal. We also note that no graphite was formed after the shear-friction processes, despite the PSZ and/or WDZ of samples S3, S5 and S8 having a strong peak $\left(26.29^{\circ}\right)$ that is very close to the graphite 002 peak $\left(26.38^{\circ}\right)$.

Note that in this study we assume that the crystalline carbon in coal, in general, consists of graphite-like layered aromatic structures plus marginal aliphatic structure (Lu et al., 2001). All structure parameters for carbon crystallite obtained using the methods described in Sect. 2.5.2 are listed in Table 3, and the representative structure parameters obtained from samples $\mathrm{S}^{*}-\mathrm{S} 8$ were also plotted as a function of apparent steady-state shear stress (Fig. 9a) and effective normal stress (Fig. 9b) measured at the shear displacement of $\sim 5.7 \mathrm{~mm}$ in the direct shear experiments. Specifically, the interlayer spacing $\left(d_{002}\right)$ of the layered graphite-like structure in the sheared coal gouges yields 3.47-3.53 A, including the PSZ and WDZ, which is lower than the $d_{002}$ value of 3.56-3.58 $\AA$ obtained for the unsheared samples $\mathrm{S}^{*}$ and S0, as seen in Table 3 and Fig. 9a. This suggests that the layered graphite-like structures in coal, i.e., condensed aromatic system, became more condensed after the shear-friction experiments. Careful inspection of Fig. 9a also indicates a thinner interlayer spacing $\left(d_{002}\right)$ measured in the PSZ compared to 

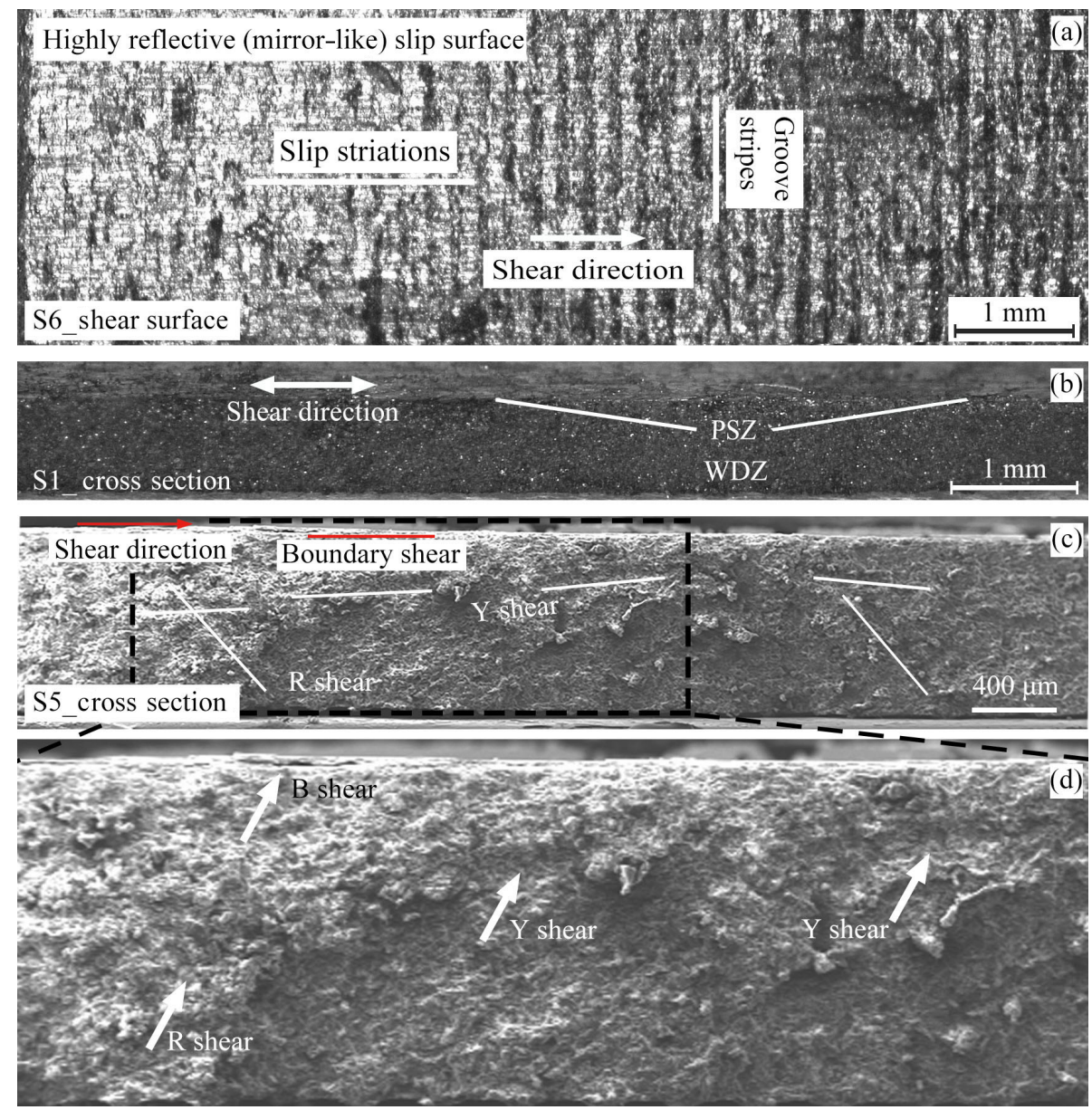

Figure 6. Microstructure of samples S1, S5 and S6 after shear deformation. Panels (a) and (b) were imaged using an optical microscope in a reflected light mode, while (c) was imaged using an SEM in secondary electron mode. (a) The shear surface of sample S6, showing a highly reflective (mirror-like) slip surface on the left-hand side of the image (below the corresponding label). (b) The cross section of sample S1 in an orientation parallel to the shear direction, indicating a principal slip zone (PSZ) and a weakly deformed zone (WDZ). (c) The cross section of sample S5 in an orientation parallel to the shear direction, showing the development of R-shear, boundary and Y-shear bands. (d) The magnification of the region marked in (c).

that measured in the WDZ for most samples, suggesting the development of layered graphite-like structures in the boundary shear band. The stacked height of crystalline carbon (i.e., $L_{\mathrm{c}}$ ) in coal increased from $\sim 13$ to $\sim 20 \AA$, while the diameter of crystalline carbon (i.e., $L_{\mathrm{a}}$ ) decreased from $20-21$ to 15-19 ̊ after the shear-friction experiments. We also note that, for most samples, the values of $L_{\mathrm{c}}$ and $L_{\mathrm{a}}$ measured in the WDZ lie between those measured in the unsheared samples and the PSZ of the sheared samples. Meanwhile, aromaticity $\left(f_{\mathrm{a}}\right)$, i.e., the ratio or fraction of aromatic carbon atoms, yields $0.44-0.49,0.43-0.64$ and $0.53-0.67$ for the unsheared samples and the WDZ and PSZ of the sheared samples, respectively. The parameter $I_{26} / I_{20}$, representative of coal rank, accordingly increased from 1.21-1.29 to 1.332.29 after the shear-friction experiments. This clearly indicates the development of the condensed aromatic system in coal upon the shear-friction processes. It is seen from
Fig. 9 that the structure parameters measured in the sheared samples, including the PSZ and WDZ, seem to be insensitive to the applied effective normal stress and the apparent steady-state shear stress measured at the shear displacement of $\sim 5.7 \mathrm{~mm}$.

\subsection{Results of Raman analysis}

The averaged normalized spectra of all samples after smoothing and background correction are plotted in Fig. 10. The D and $\mathrm{G}$ bands were observed at $\sim 1360$ and $\sim 1600 \mathrm{~cm}^{-1}$ for all samples, respectively. Both the $\mathrm{D}$ and $\mathrm{G}$ bands observed in the sheared samples are more narrow than those observed in the unsheared samples. Also, the D band observed in the sheared samples slightly shifted to the left, while the G band slightly shifted to the right compared to those observed in the unsheared samples. This likely reflects an increase in the 

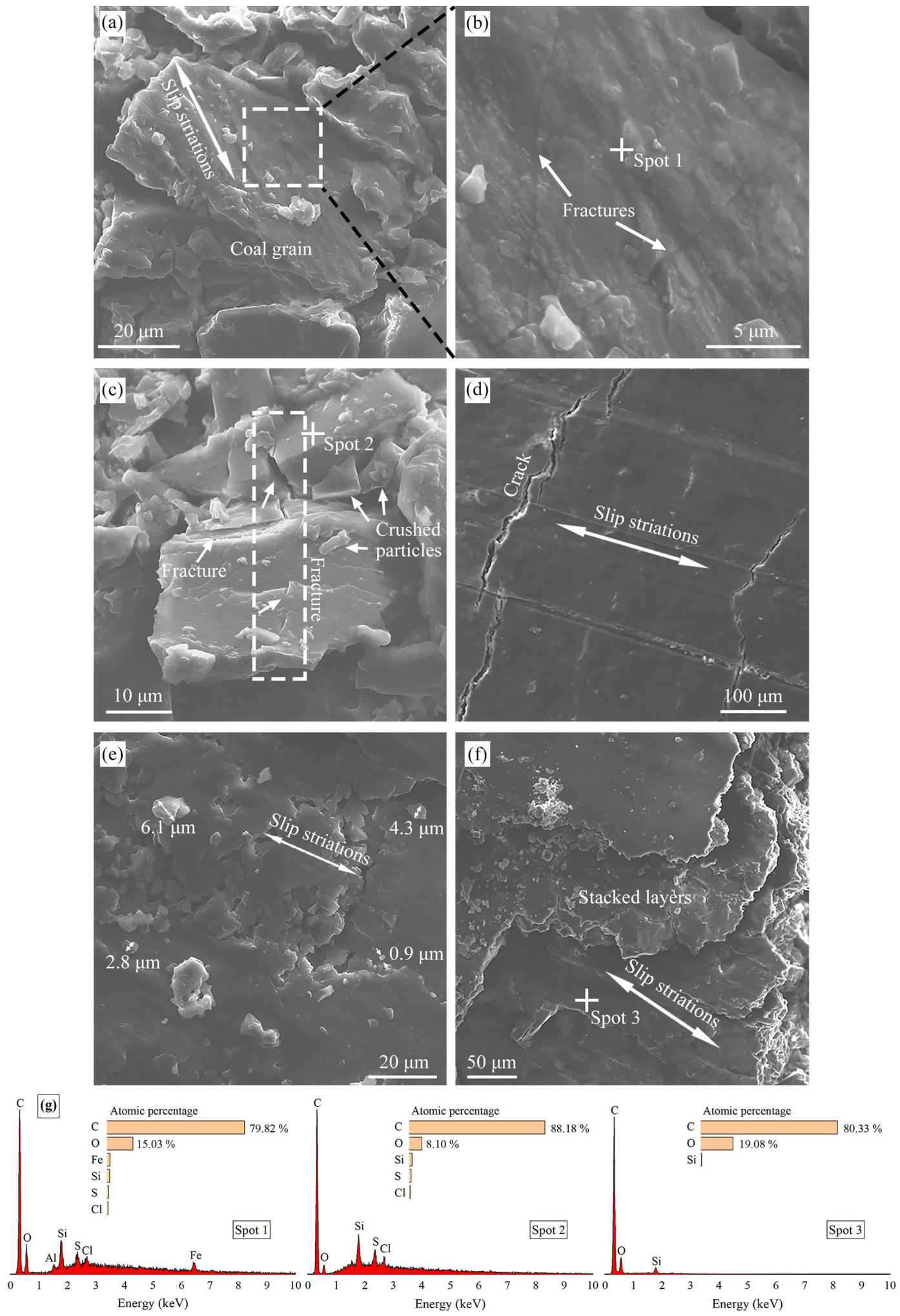

Figure 7. SEM secondary electron images of samples S4 (a, b, c, f) and S5 (d, e) after the direct shear experiments and EDS data (g) for the representative spots. (a) Randomly oriented coal grain with slip striations in the WDZ, located in the cross section of S4. (b) The fractures inside the coal grain shown in (a). (c) Fractures inside coal grains to form crushed particles. (d) The central region of the shear surface of sample S5, showing cracks and slip striations. (e) Small coal particles $(<\sim 10 \mu \mathrm{m})$ in the broken edge of the shear surface. (f) Remarkable layered structure at the margins of the slip zone, likely reflecting an interaction between the PSZ and WDZ as well as the role of the PSZ during the friction process. (g) EDS data for three spots located in S4, showing the elemental composition of the spots. 


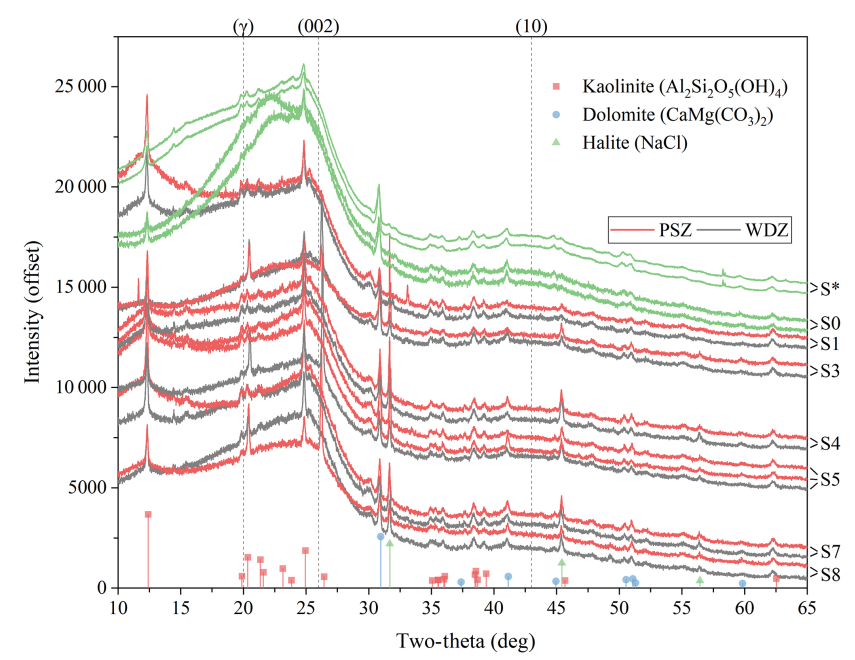

Figure 8. X-ray diffractograms for starting coal powder $S^{*}$, precompacted coal (unsheared) sample S0, and sheared samples S1-S8 except S2 and S6. The minor peaks are marked by possible minerals using points. The red and black lines represent the XRD profile for samples retrieved from the principal boundary slip zone (PSZ) and the weakly deformed zone (WDZ). Note that the intensity for sample $S^{*}$ was reduced 10 times to a comparable scale.

maturity of coal after the shear-friction experiments. The Raman parameters described in Sect. 2.5.3 were obtained from Fig. 10 and are listed in Table 4. As shown in Fig. 11a and $\mathrm{b}$, the Raman parameters for samples S0 and the PSZ of S1S8 were also plotted as a function of apparent steady-state shear stress and effective normal stress measured at the shear displacement of $\sim 5.7 \mathrm{~mm}$ in the direct shear experiments. It shows, in general, an obvious difference in the Raman parameters between the sheared coal samples (S1-S8) and the unsheared sample S0, suggesting the role of shear and friction. Particularly, G-FWHM values decrease from $91.3 \mathrm{~cm}^{-1}$ measured in the unsheared samples to $71.7-79.7 \mathrm{~cm}^{-1}$ measured in the sheared samples. RBS and SI values increase from $227.7 \mathrm{~cm}^{-1}$ and 3.27 measured in the unsheared samples to $239.3-256.7 \mathrm{~cm}^{-1}$ and $3.65-4.26$ measured in the sheared samples. Conversely, we found similar parameter values of $I_{\mathrm{D}} / I_{\mathrm{G}}$ for all samples, yielding $0.543-0.561$, which is not sensitive to the shear deformation. It is also seen from Fig. 11a and $\mathrm{b}$ that all Raman parameters measured in the sheared samples are not sensitive to the applied effective normal stress and apparent steady-state shear stress. Recall that we measured Raman spectra in the WDZ only for sample S4. We plotted the Raman parameters measured in samples $S^{*}$, S0 and S4 in Fig. 11c, indicating a slight difference between the WDZ and PSZ, as well as a difference between $\mathrm{S}^{*}$ and S0.

\section{Discussion}

All experiments show significant slip-weakening behavior, from a peak friction coefficient of $\sim 0.5$ to a near-steadystate value of $\sim 0.3$. Post-microstructure observation indicates the development of shear bands. In addition, XRD and Raman analysis suggests that the shear deformation may change the molecular structure and maturity of coal in the shear bands. Furthermore, the VS experiments showed that (a) little effect of effective normal stress on frictional strength and $(a-b)$ values was found; (b) $(a-b)$ values systemically became smaller at higher velocity steps; and (c) the samples exposed to DI water at a pore pressure of $15 \mathrm{MPa}$ exhibited velocity-strengthening behavior at velocity steps of $0.1-10 \mu \mathrm{m} \mathrm{s}^{-1}$, but velocity-weakening behavior at velocity steps of $10-100 \mu \mathrm{m} \mathrm{s}^{-1}$, as opposed to the sample under vacuum-dry conditions that showed velocity-weakening behavior at almost all velocity steps employed in this study. The SHS experiment demonstrated minor frictional healing $(\beta=0.006 \pm 0.001)$ in a water-saturated coal gouge sample. In the following, we first attempt to elucidate the development of the molecular structure of coal upon shear deformation. We then discuss whether the shear-induced molecular structural change dominated the marked slip-weakening behavior observed in coal gouges. We also discuss the velocityor rate-dependent friction of coal. Finally, we consider, in a broad way, the implications of our findings for the frictional strength and (induced) seismic potential of coal-rich or organic-rich faults.

\subsection{Development of the molecular structure and maturity of coal in shear bands}

Following Lu et al. (2001), we assume our bituminous coal consists of graphite-like crystalline (i.e., a condensed aromatic system) and amorphous (i.e., nonaromatic system) forms of carbon. Our XRD results on the unsheared samples ( $\mathrm{S}^{*}$ and $\mathrm{S} 0$ ) show the structure of the graphite-like crystalline carbon in bituminous coal, yielding an interlayer spacing $\left(d_{002}\right)$ of $\sim 3.56 \AA$, a crystallite diameter $\left(L_{\mathrm{c}}\right)$ of $\sim 13.5 \AA$, a stacked height $\left(L_{\mathrm{a}}\right)$ of $\sim 19 \AA$ and aromaticity $\left(f_{\mathrm{a}}\right)$ of $\sim 0.47$. These parameter values are consistent with those of similar bituminous coal reported by K. Li et al. (2015), Okolo et al. (2015) and Zhang et al. (2015). Note that the parameter values of $L_{\mathrm{c}}$ and $L_{\mathrm{a}}$ that were calculated using Scherrer's equation may be larger than the real size (Lu et al., 2001) and that the presence of mineral peaks, particularly in the $2 \theta$ range of $27-50^{\circ}$, may also influence the fitting process (i.e., fitting a Gaussian peak to the $002, \gamma$ and 10 bands) and may accordingly influence the accuracy of the structure parameter values. However, these influences should be consistent for all samples. We therefore believe that the values of the structure parameters shown in Table 3 and Fig. 9 could be influenced by these factors as a systemic error and accordingly would not change the trend or results that we ob- 
Table 3. Coal crystal structure parameters determined from XRD profiles.

\begin{tabular}{|c|c|c|c|c|c|c|c|c|c|c|}
\hline \multirow[t]{5}{*}{ Sam. } & & $\begin{array}{r}2 \theta_{002} \\
\left(^{\circ}\right)\end{array}$ & $\begin{array}{r}2 \theta_{10} \\
\left(^{\circ}\right)\end{array}$ & $\begin{array}{r}\beta_{002} \\
\left(^{\circ}\right)\end{array}$ & $\begin{array}{l}\beta_{10} \\
\left({ }^{\circ}\right)\end{array}$ & $\begin{array}{r}d_{002} \\
(\AA)\end{array}$ & $\begin{array}{l}L_{\mathrm{c}} \\
(\AA)\end{array}$ & $\begin{array}{r}L_{\mathrm{a}} \\
(\AA)\end{array}$ & $I_{26} / I_{20}$ & $f_{\mathrm{a}}$ \\
\hline & \multirow[t]{2}{*}{$\mathrm{S}^{*}$} & 24.81 & 43.59 & 5.81 & 8.94 & 3.58 & 14.26 & 20.22 & 1.29 & 0.44 \\
\hline & & 24.93 & 43.59 & 5.48 & 8.38 & \pm 0.01 & \pm 0.59 & \pm 0.92 & \pm 0.10 & \pm 0.04 \\
\hline & \multirow[t]{2}{*}{ So } & 25.02 & 43.72 & 6.10 & 8.13 & 3.56 & 12.87 & 21.46 & 1.21 & 0.49 \\
\hline & & 24.94 & 43.80 & 6.41 & 8.18 & \pm 0.01 & \pm 0.45 & \pm 0.09 & \pm 0.03 & \pm 0.03 \\
\hline \multirow[t]{7}{*}{ PSZ } & $\mathrm{S} 1$ & 25.57 & 44.73 & 3.88 & 11.79 & 3.48 & 20.76 & 14.90 & 1.72 & 0.56 \\
\hline & S3 & 25.25 & 43.96 & 5.28 & 9.13 & 3.52 & 15.25 & 19.18 & 1.33 & 0.53 \\
\hline & S4 & 25.62 & 44.17 & 3.77 & 11.04 & 3.47 & 21.37 & 15.88 & 1.76 & 0.56 \\
\hline & \multirow[t]{2}{*}{ S5 } & 25.46 & 44.30 & 3.92 & 10.82 & 3.49 & 20.22 & 15.97 & 2.23 & 0.67 \\
\hline & & 25.51 & 44.30 & 4.05 & 11.15 & \pm 0.00 & \pm 0.46 & \pm 0.34 & \pm 0.00 & \pm 0.00 \\
\hline & S7 & 25.57 & 44.36 & 4.06 & 10.58 & 3.48 & 19.84 & 16.58 & 1.96 & 0.61 \\
\hline & S8 & 25.21 & 43.82 & 5.18 & 9.10 & 3.53 & 15.54 & 19.24 & 1.69 & 0.61 \\
\hline \multirow[t]{6}{*}{ WDZ } & $\mathrm{S} 1$ & 25.22 & 44.17 & 4.61 & 10.96 & 3.53 & 17.46 & 15.99 & 2.11 & 0.64 \\
\hline & S3 & 25.55 & 43.80 & 4.51 & 9.52 & 3.48 & 17.86 & 18.39 & 1.51 & 0.51 \\
\hline & S4 & 25.34 & 44.11 & 4.49 & 8.97 & 3.51 & 17.93 & 19.54 & 2.29 & 0.63 \\
\hline & S5 & 25.40 & 43.97 & 4.55 & 10.77 & 3.50 & 17.70 & 16.26 & 1.58 & 0.54 \\
\hline & S7 & 25.28 & 44.21 & 4.65 & 7.74 & 3.52 & 17.31 & 22.65 & 1.98 & 0.60 \\
\hline & S8 & 25.54 & 43.67 & 4.27 & 10.27 & 3.48 & 18.86 & 17.04 & 1.16 & 0.43 \\
\hline
\end{tabular}

PSZ and WDZ represent the principal boundary slip zone and weakly deformed zone retrieved from the sheared samples. Note that the parameters for samples $\mathrm{S}^{*}, \mathrm{~S} 0$ and S5 are mean values associated with the standard deviation that were obtained from reproducible tests.

Table 4. Parameters obtained from normalized Raman spectra using the method reported by Henry et al. (2018).

\begin{tabular}{|c|c|c|c|c|c|c|c|c|c|c|c|c|}
\hline Sam. & & $\mathrm{S}^{*}$ & S4* & S0 & $\mathrm{S} 1$ & $\mathrm{~S} 2$ & S3 & S4 & S5 & S6 & S7 & S8 \\
\hline \multirow{2}{*}{$\begin{array}{l}\text { D position } \\
\text { SD }\end{array}$} & \multirow{2}{*}{$\left(\mathrm{cm}^{-1}\right)$} & 1368 & 1354 & 1369 & 1359 & 1364 & 1361 & 1362 & 1361 & 1352 & 1348 & 1347 \\
\hline & & I & 10.1 & 7.0 & 8.5 & 1.5 & 7.5 & 8.7 & 2.5 & 8.4 & 2.9 & 3.0 \\
\hline \multirow{2}{*}{$\begin{array}{l}\text { D-FWHM } \\
\text { SD }\end{array}$} & \multirow{2}{*}{$\left(\mathrm{cm}^{-1}\right)$} & NA & NA & NA & 209.4 & NA & NA & NA & NA & NA & 217.3 & 201.3 \\
\hline & & I & NA & NA & 7.7 & NA & NA & NA & NA & NA & 4.6 & 10.1 \\
\hline \multirow{2}{*}{$\begin{array}{l}\text { G position } \\
\text { SD }\end{array}$} & \multirow{2}{*}{$\left(\mathrm{cm}^{-1}\right)$} & 1601 & 1601 & 1597 & 1603 & 1601 & 1601 & 1602 & 1601 & 1603 & 1601 & 1604 \\
\hline & & I & 0.0 & 3.5 & 1.5 & 0.0 & 0.0 & 1.2 & 0.6 & 1.7 & 0.6 & 0.6 \\
\hline \multirow{2}{*}{$\begin{array}{l}\text { G-FWHM } \\
\text { SD }\end{array}$} & \multirow{2}{*}{$\left(\mathrm{cm}^{-1}\right)$} & 84.0 & 78.0 & 91.3 & 73.9 & 77.7 & 79.0 & 79.7 & 78.0 & 77.0 & 77.3 & 71.7 \\
\hline & & I & 4.6 & 4.5 & 4.4 & 0.6 & 2.6 & 4.0 & 1.0 & 6.3 & 0.6 & 3.5 \\
\hline \multirow{2}{*}{$\begin{array}{l}\text { RBS } \\
\text { SD }\end{array}$} & \multirow{2}{*}{$\left(\mathrm{cm}^{-1}\right)$} & 233.0 & 246.7 & 227.7 & 244.5 & 237.3 & 240.0 & 239.7 & 239.3 & 250.5 & 252.3 & 256.7 \\
\hline & & I & 10.1 & 10.3 & 9.8 & 1.5 & 7.5 & 9.2 & 3.1 & 10.1 & 3.2 & 3.1 \\
\hline \multirow{2}{*}{$\begin{array}{l}I_{\mathrm{D}} / I_{\mathrm{G}} \\
\mathrm{SD}\end{array}$} & \multirow[t]{2}{*}{1} & 0.540 & 0.548 & 0.543 & 0.553 & 0.555 & 0.561 & 0.543 & 0.553 & 0.553 & 0.552 & 0.551 \\
\hline & & I & 0.024 & 0.004 & 0.009 & 0.006 & 0.014 & 0.006 & 0.013 & 0.019 & 0.011 & 0.003 \\
\hline SI & \multirow{2}{*}{ I } & 3.70 & 3.84 & 3.27 & 4.26 & 3.65 & 3.78 & 3.76 & 3.65 & 3.75 & 3.79 & 4.08 \\
\hline SD & & I & 0.65 & 0.34 & 0.32 & 0.10 & 0.33 & 0.09 & 0.08 & 0.30 & 0.10 & 0.13 \\
\hline
\end{tabular}

S4* represents the weakly deformed zone of sample S4. NA: this value cannot be obtained due to the limitations of the processing method described in Sect. 2.5.3. 
(a)

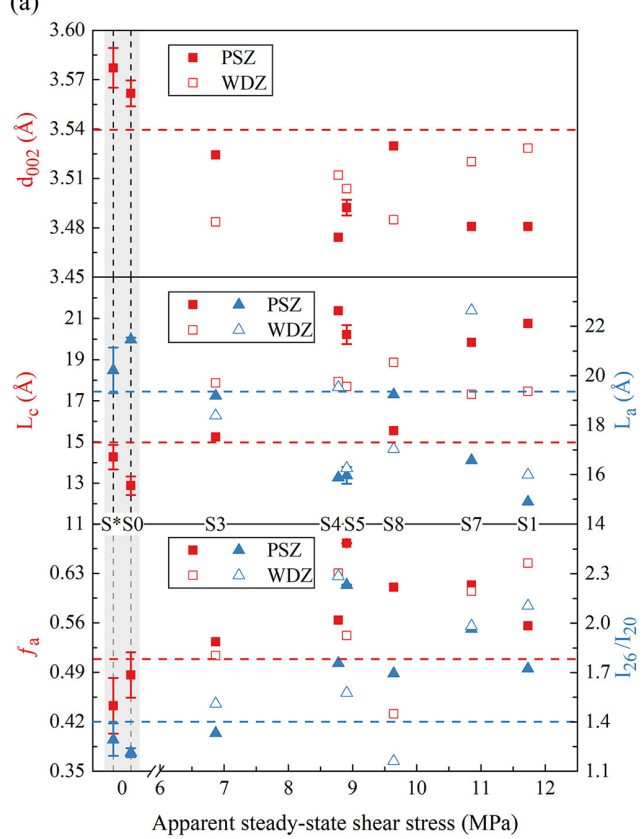

(b)

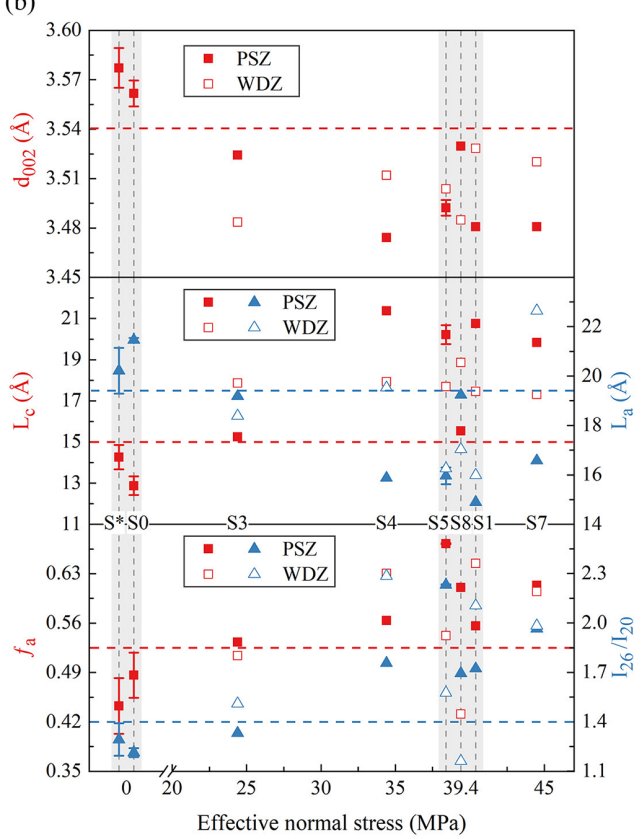

Figure 9. Representative crystal structure parameters obtained from samples $S^{*}-S 8$ versus apparent steady-state shear stress measured at a shear displacement of $\sim 5.7 \mathrm{~mm}$ and effective normal stress with the corresponding sample number in (a) and (b), respectively. The data offset is given in the grey area; i.e., the data plotted on the vertical dashed lines were obtained at $0 \mathrm{MPa}$ (non-sheared samples) or $\sim 40 \mathrm{MPa}$ effective normal stress but are horizontally offset here for readability. Solid and hollow squares or triangles represent the values for the PSZ and WDZ retrieved from the sheared samples, respectively. The error bars for samples S*, S0 and S5 are the standard deviations.

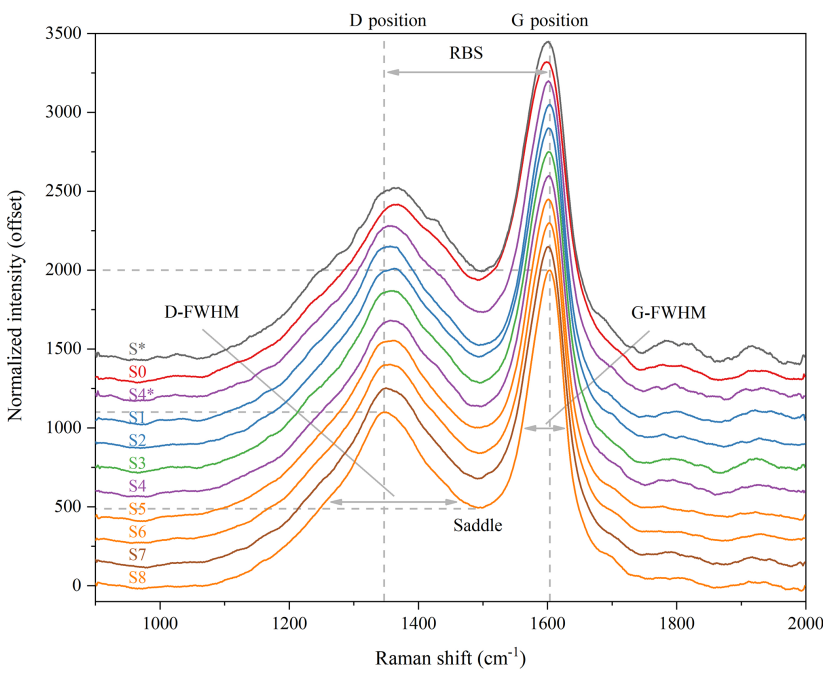

Figure 10. The processed Raman spectra of coal samples, showing the spectra differences between unsheared samples ( $\mathrm{S}^{*}$ and $\mathrm{S} 0$ ) and sheared samples (S1-S8). Note that different colors mean different experimental conditions, and $\mathrm{S} 4 *$ represents the weakly deformed zone of sample S4. Some important parameters were marked according to Henry et al. (2018). served in Fig. 9. Furthermore, the minor standard deviations shown in the measurements on samples $\mathrm{S}^{*}$, S0 and S5 indicate a good reproduction of our XRD measurements. As a result, we believe that our XRD results on both unsheared and sheared samples, particularly in the PSZ, indeed demonstrate that the structure of graphite-like crystalline carbon became more uniform after the shear-friction experiments; i.e., $d_{002}$ became smaller, while $L_{\mathrm{c}}, f_{\mathrm{a}}$ and $I_{26} / I_{20}$ became larger (see Fig. 9 and Table 3). Note that our results show that $L_{\mathrm{a}}$ became smaller upon shear-friction experiments, which is also observed in coal ranking from low-volatile bituminous to semi-anthracite during the coalification process (Jiang et al., 2019). This development of molecular structure likely reflects an increase in the maturity of the coal samples, which is in good agreement with our observations from Raman spectra. As is known, many Raman parameters are correlated with a maturity index (such as vitrinite reflectance (VR) and total fixed carbon), and correlations are widely reported (Wilkins et al., 2014; Schito et al., 2017; Henry et al., 2018, 2019; Zhang and Li, 2019). Generally, G-FWHM, D-FWHM and $I_{\mathrm{D}} / I_{\mathrm{G}}$ are negatively related to measured $\% \mathrm{VR}$, while RBS and the saddle index are opposite. To better illustrate the change in coal maturity from our Raman spectra, we plotted two representative correlations between Raman parameters and maturity reported by Henry et al. (2019) in Fig. 11a, i.e., G-FWHM vs. VR and RBS vs. VR. It is clearly seen in Fig. 11a that the apparent differences in Raman parameters 


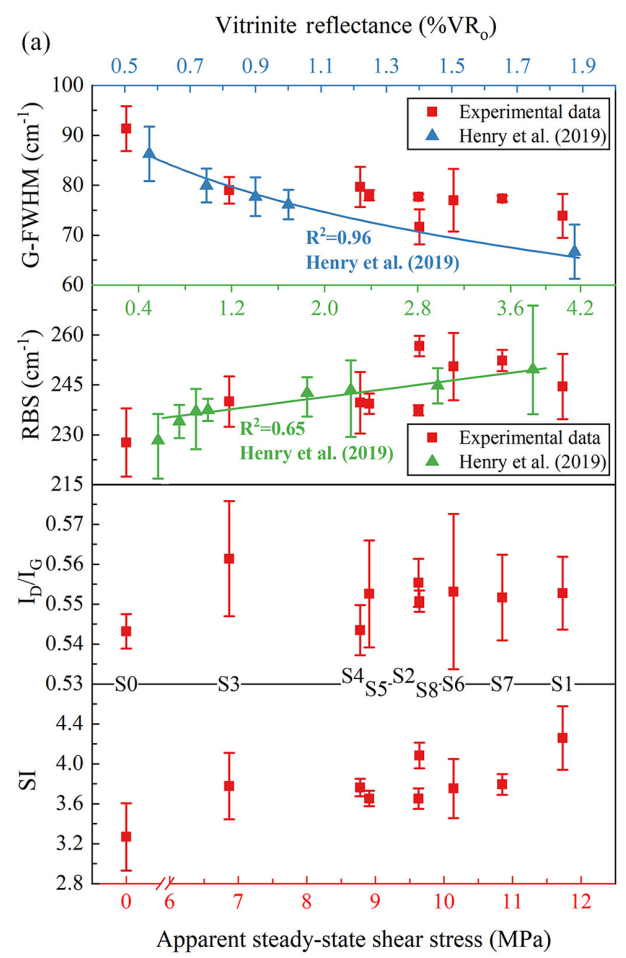

(b)

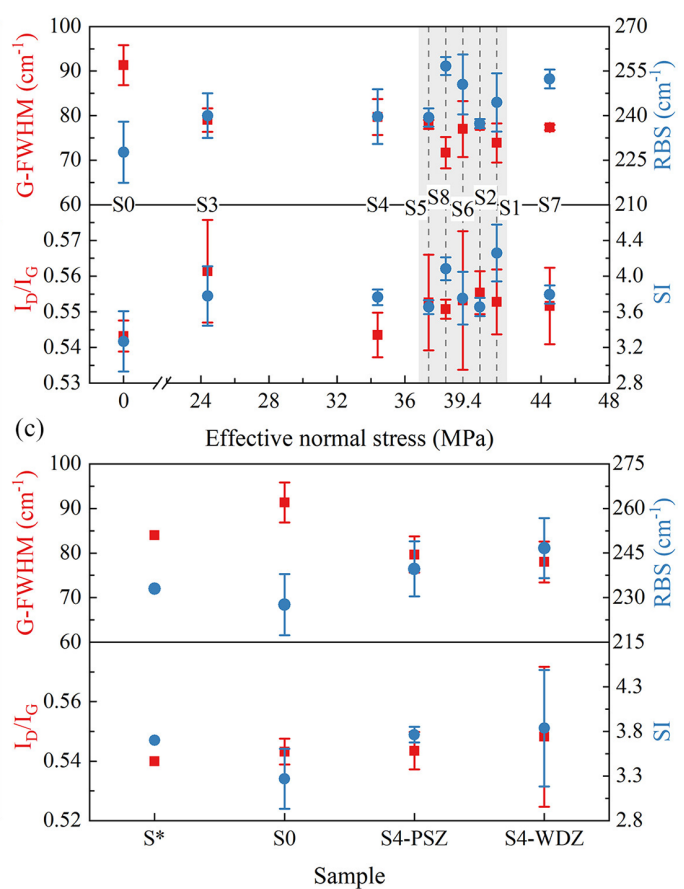

Figure 11. Representative Raman parameters as a function of apparent steady-state shear stress and effective normal stress plotted in (a) and (b), respectively. The difference in Raman parameters between S*, S0, S4-PSZ, and S4-WDZ is shown in (c). In (b), the data offset is given in the grey area; i.e., the data plotted on the vertical dashed lines were obtained at $\sim 40 \mathrm{MPa}$ effective normal stress but are horizontally offset here for readability. Note that the relations of G-FWHM vs. vitrinite reflectance and RBS vs. vitrinite reflectance plotted in (a) were obtained from Henry et al. (2019). The error bars are the standard deviations.

(G-FWHM and RBS) between the sheared and unsheared samples show that the coal maturity was improved after the shear-friction experiments. We also note that the petrological and chemical analyses showed our coal sample has a vitrinite reflectance of $0.77 \pm 0.05 \%$, which is larger than the values of VR of the unsheared samples $S^{*}(\sim 0.6)$ and S0 $(\sim 0.4$ $0.5)$ obtained from the correlations shown in Fig. 11a. This suggests it would be difficult to quantitatively determine the maturity increase upon the shear-friction process using these correlations between Raman parameters and VR. Nonetheless, these correlations shown in Fig. 11a, we believe, have demonstrated that the Raman parameters can reflect coal maturity change, and, once again, the change in Raman parameters accordingly indicates an increase in coal maturity upon the shear-friction experiments.

We now attempt to elucidate the likely mechanisms responsible for the development of the molecular structure and maturity of coal during the shear-friction process. It is well known that the molecular structure and maturity of coal can be changed under conditions of high temperature and pressure at a geological timescale during metamorphism (Bonijoly et al., 1982; Oberlin, 1984; Buseck and Huang, 1985; Buseck and Beyssac, 2014). Research on the pyrolysis of bituminous coal showed that, when the temperature is be- low $\sim 200^{\circ} \mathrm{C}$, the volatilization of small molecules and the slight breaking of aliphatic chains can occur to produce only trace amounts of gas (e.g., $\mathrm{CO}$ and/or $\mathrm{CH}_{4}$ ), while above $\sim 300-400^{\circ} \mathrm{C}$ the number of most functional groups decreases rapidly with the cracking of $\mathrm{C}-\mathrm{H}$ bonds and $\mathrm{C}-\mathrm{C}$ bonds, generating a large amount of gas (Öztaş and Yürüm, 2000; Zhao et al., 2007; Niu et al., 2016; Kaneki et al., 2018). High-resolution TEM, Raman spectroscopy and FTIR analysis performed on the tectonically deformed coals, which often accumulate many shear strains associated with strain energy, suggests that tectonic deformation can improve the ordering of aromatic structure and reduce the content of hydrogen and oxygen (Ju et al., 2005; Cao et al., 2007; Xu et al., 2014; Pan et al., 2017; Song et al., 2018). Therefore, returning to our experiments, under the PT conditions employed (i.e., $25-45 \mathrm{MPa}$ effective normal stress and $100^{\circ} \mathrm{C}$ ), we believe that the molecular structure of bituminous coal is very unlikely to be changed over hours without the shearfriction process (Hou et al., 2014; Xu et al., 2014). Moreover, the slip rates $\left(0.1-100 \mu \mathrm{m} \mathrm{s}^{-1}\right)$ employed in our experiments mean that the development of molecular structure and maturity due to sample-scale frictional heating effects seen in high-velocity friction experiments can be eliminated (Rice, 2006; Di Toro et al., 2011; Aharonov and Scholz, 
2018). In addition, we infer that flash-heating mechanisms reported by Kaneki and Hirono (2019) may play a minor role, as the structural and Raman parameters are both insensitive to applied effective normal stress. As a result, we infer that the improvement of molecular structure and maturity observed in our experiments is caused by shear deformation (i.e., strain localization in the shear bands) associated with strain energy (Hou et al., 2017). Similarly, an improvement of the molecular structure of anthracite coal was also observed in creep compaction experiments at axial strain rates of $1.3 \times 10^{-6}-1.3 \times 10^{-4} \mathrm{~s}^{-1}$ performed at a confining pressure of $500 \mathrm{MPa}$ and temperatures of $300-600^{\circ} \mathrm{C}$ (Ross and Bustin, 1990; Ross et al., 1991). Ross and Bustin (1990) and Ross et al. (1991), based on TEM observations on deformed samples, found that stacks of aromatic layers in coal became more ordered and were progressively aligned in the plane of flattening during deformation; i.e., the organization of crystalline carbon was significantly improved during the deformation but not enough to form graphite. Aside from creep compaction experiments, Bustin et al. (1995a, b) also performed simple shear experiments at a confining pressure of 0.8 or $1 \mathrm{GPa}$ on bituminous and anthracite coal at temperatures of $400-900{ }^{\circ} \mathrm{C}$, employing shear strain rates of $1 \times 10^{-5}-1 \times 10^{-6} \mathrm{~s}^{-1}$ as opposed to our shear strain rates of $\sim 1 \times 10^{-4}-1 \times 10^{-1} \mathrm{~s}^{-1}$ and PT conditions. They found, only for the sheared samples, that graphite was formed from bituminous coal initially at $800^{\circ} \mathrm{C}$ and commonly at $900^{\circ} \mathrm{C}$, while from anthracite coal it was formed initially at $600{ }^{\circ} \mathrm{C}$ and commonly at $900^{\circ} \mathrm{C}$. Similar findings were also reported by Wilks et al. (1993). They all suggest that the improvement of molecular structure in coal observed at relatively low PT conditions and at lab timescales was caused by shear strain that can largely lower the activation energy for the graphitization process of coal (Ross and Bustin, 1990; Ross et al., 1991; Wilks et al., 1993; Bustin et al., 1995a, b). Conversely, Nakamura et al. (2015) found that graphite in natural fault zones releases strain energy by microscale and nanoscale delamination and size reduction as a function of the degree of deformation, leading to amorphization. This shear-induced (or strain-induced) graphitization process as a mechanism, from the point view of microstructure, may mainly consist of (a) promoting preferred orientation and the rearrangement of aromatic structure systems; and (b) favoring the motion and modulation of structural defects to produce a highly ordered graphite structure (e.g., Beyssac et al., 2002; Wang et al., 2019).

\subsection{Mechanisms causing slip weakening}

All of our experiments have shown a marked slip-weakening behavior of coal at the initial displacement of $\sim 1-2 \mathrm{~mm}$ (Fig. 3); i.e., the friction coefficient decreased from a peak value approaching $\sim 0.5$ to a near-steady-state value around only 0.3 . Similar slip-weakening behavior was also observed on simulated coal-shale gouges with coal content $\geq 50$ vol $\%$
(Liu et al., 2020) and synthetic graphite gouges (Kirilova et al., 2018) under similar experimental conditions. Kirilova et al. (2018) inferred that the slip-weakening behavior seen in the synthetic graphite gouge could be related to the degree of the order of crystal sheet structure in the shear zone (Morrow et al., 2000; Rutter et al., 2013). Recall that mineral content in our coal samples is $\sim 5 \%$ only, and EDS data show little mineral content in the WDZ and PSZ. This all suggests that the presence of minerals should play little role in controlling this significant slip-weakening behavior. Moreover, the temperature and sliding rates employed in our experiments, together with our XRD results, mean that lubrication effects (Di Toro et al., 2011) due to samplescale frictional heating and graphitization effects widely seen in high-velocity friction experiments (e.g., Oohashi et al., 2011) can be eliminated. This marked slip-weakening behavior was observed in both samples under vacuum-dry conditions and samples exposed to DI water at $15 \mathrm{MPa}$. This suggests that local overpressure effects of DI pore water as a mechanism (e.g., Faulkner et al., 2018) can be eliminated. On the other hand, our microstructure observations on the deformed gouges shown in Figs. 6 and 7 indicate the development of R-, B-, Y-shear bands. Following Logan et al. (1992), strain localization in shear bands may be one of the mechanisms responsible for this slip-weakening behavior of coal. Importantly, our XRD and Raman analyses on the PSZ of the sheared samples suggest the crystallinity was improved in the shear bands upon strain localization associated with strain energy (also see Sect. 4.1). This shear-enhanced crystallinity was also observed in natural (deformed) carbonaceous materials in a fault zone (Kuo et al., 2018; Wang et al., 2019), which likely results in a reduction in frictional strength (Ruan and Bhushan, 1994; Morrow et al., 2000; Moore and Lockner, 2004). Significantly, in high-maturity materials such as graphite, the structural disorder is enhanced by shear deformation (Nakamura et al., 2015; Kirilova et al., 2018; Kaneki and Hirono, 2019). As reported by Oohashi et al. (2011), the peak and steady-state friction of amorphous carbon at low slip rates yields $\sim 0.5$, while graphite yields $\sim 0.1$, suggesting that the molecular structure of carbon may play a significant role in controlling frictional properties. Recall that our XRD showed that no graphite was formed after the friction experiments. We therefore infer that the improvement of crystallinity in coal may dominate the steadystate friction of coal approaching $\sim 0.3$, which lies between the steady-state friction of amorphous carbon and graphite. As a result, this all suggests that the marked slip-weakening behavior of coal could largely be attributed to both the development of R-, B- and Y-shear bands and an increase in the crystallinity of coal in the shear bands upon strain localization. However, we also note that small amounts of gas (e.g., $\mathrm{CO}$ and/or $\mathrm{CH}_{4}$ ) might potentially be produced upon the volatilization of small molecules and the slight breaking of aliphatic chains during shear deformation. It still remains unknown whether this process occurred in our experiments 
and how this process would influence slip-weakening behavior. Conversely, Fan and Liu (2019) found no slip-weakening behavior in friction experiments on precut bituminous coal blocks by employing shear rates of $1-10 \mu \mathrm{m} \mathrm{s}^{-1}$ to a total shear displacement of $\sim 7 \mathrm{~mm}$ at an effective normal stress of $2 \mathrm{MPa}$. This difference between the findings reported by Fan and Liu (2019) and our results suggests that strain energy may play a significant role in enhancing coal crystallinity and in reducing frictional strength. Unfortunately, we cannot directly investigate the effect of strain energy on the development of crystal structure in the present experiments, as we have insufficient experimental data. To further test the hypothesis that strain energy accumulated in the shear bands enhances the crystallinity of coal, we will initiate another study involving high-resolution BIB-SEM, Raman and XRD observations on coal gouges subjected to wellcontrolled shear displacements, such as 1,2, 4 and $5 \mathrm{~mm}$ and beyond, at low and high normal effective stresses.

\subsection{Velocity dependence of friction}

Our velocity stepping (VS) experiments, from an RSF point of view, indicate that sliding velocity and pore fluid play roles in the rate dependence of friction of coal (see Fig. 4b). In an attempt to better illustrate these effects, we plot the $(a-b)$ values obtained from the experiments S2-S7 against up-step sliding velocity shown in Fig. 12. We note that almost all wet coal samples S3-S7 (except S5) show positive $(a-b)$ values in the velocity stepping of $1-10 \mu \mathrm{m} \mathrm{s}^{-1}$. Similar velocity-strengthening behavior of precut bituminous coal exposed to various fluids (helium, carbon dioxide, water and moisturized methane) at an effective normal stress of $2 \mathrm{MPa}$ in sliding velocities of $1-10 \mu \mathrm{m} \mathrm{s}^{-1}$ was also reported by Fan and Liu (2019). Careful inspection of Fig. 12 shows a clear, systematic tendency for a transition from velocity strengthening to velocity weakening, regardless of the experimental conditions employed in this study. Interestingly, the transition occurs at a slip rate of $\sim 10 \mu \mathrm{m} \mathrm{s}^{-1}$ in samples S3S7 exposed to DI water at $15 \mathrm{MPa}$ but may occur at a slip rate of $\sim 1 \mu \mathrm{m} \mathrm{s}^{-1}$ in sample S2 under vacuum-dry conditions. As this transition from velocity strengthening to velocity weakening is seen both in vacuum-dry samples and in samples exposed to pore water at $15 \mathrm{MPa}$, we infer that the local fluid overpressure effects (e.g., Faulkner et al., 2018) may play a minor role. On the other hand, we note that, unlike mineral gouges, coal exhibits marked stress-strainsorption behavior when exposed to water and/or gas (Liu et al., 2016, 2018). This behavior leads to swelling or shrinkage strains that strongly depend on the chemical activity (pressure) of the adsorbing fluid as well as on the Terzaghi effective stress supported by the solid grain framework. Such effects could conceivably result in competition between compaction and dilatation during the shearing of a coal gouge, leading to a complex rate dependence of friction similar to that produced by competition between dilatant granular flow

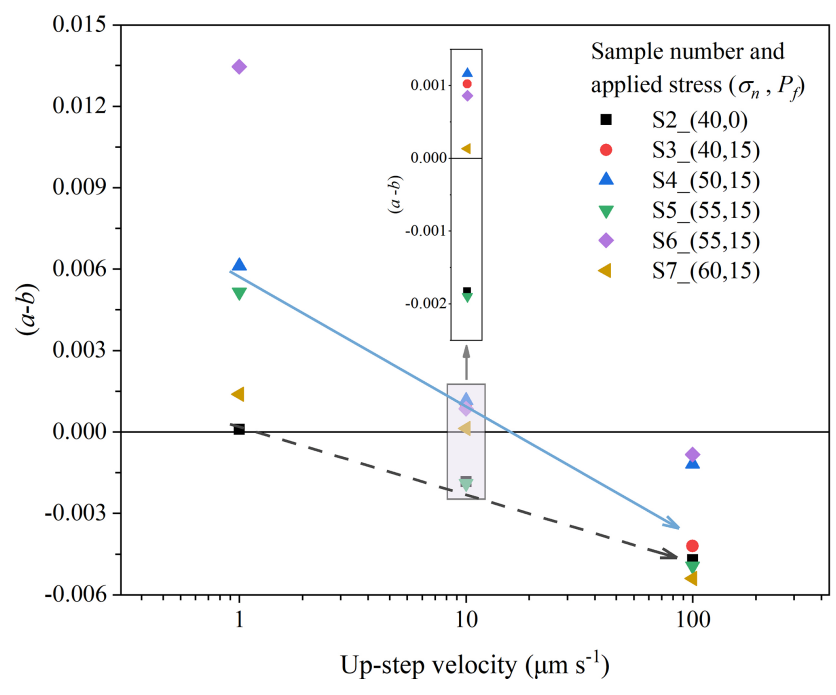

Figure 12. The $(a-b)$ values obtained from experiments S2-S7 versus up-step velocity, showing a transition from velocity strengthening to velocity weakening.

and compaction by pressure solution seen in mineral gouges (Niemeijer and Spiers, 2007; Chen and Spiers, 2016). In the following, we attempt to determine whether the above mechanism proposed by Niemeijer and Spiers (2007) and Chen and Spiers (2016) can logically explain the observed transitions.

We first focus on the coal sample under vacuum-dry conditions, in which the transition from velocity strengthening to weakening occurred at a sliding velocity of $\sim 1 \mu \mathrm{m} \mathrm{s}^{-1}$. This, following Niemeijer and Spiers (2007), suggests that for the vacuum-dry coal, the rate of compaction was similar to the dilatation rate during shear deformation at the imposed sliding velocities of $\sim 1-100 \mu \mathrm{m} \mathrm{s}^{-1}$. This may be reasonable because our XRD results, as well as the experimental results reported by the literature (Ross and Bustin, 1990; Ross et al., 1991), suggest that shear deformation (strain) changes the coal molecular structure so that stacks of aromatic layers become more uniformly packed, thus enhancing the rate of compaction to the same order as the rate of the dilatation process at sliding velocities $>\sim 1 \mu \mathrm{m} \mathrm{s}^{-1}$. Indeed, as seen in oedometer-type (1D) compaction creep experiments performed by Liu et al. (2018) using coal powders from the same source as the present study, wet coal powder exhibits much larger compaction strains than vacuum-dry coal, as well as an increase in compaction rate of 1-2 orders of magnitude. This is broadly consistent with the compaction strains estimated from the thickness change in the present wet versus vacuum-dry samples measured before versus after the experiments. This is clearly seen in Table 1, which shows $19 \%-30 \%$ compaction strain in wet experiments S3S8 compared with 10\%-19\% compaction in dry samples S1 and S2. According to Liu et al. (2018), pore water enhances the compaction of coal powder through (a) permanent time- 
dependent compaction (creep) and (b) the thermodynamic effect of a stress-driven reduction in water sorption capacity as well as an associated reduction in swelling with respect to dry material. In this case, enhanced compaction rates in the wet coal samples compared to vacuum-dry samples may dominate the competition against dilation at sliding velocities of $\sim 1-10 \mu \mathrm{m} \mathrm{s}^{-1}$, thus promoting velocity strengthening. As a result, our present study suggests that the microphysical model developed by Chen and Spiers (2016) and Niemeijer and Spiers (2007) may logically explain the observed rate dependence of friction. However, other mechanisms cannot be completely eliminated. More research is needed for a better understanding of such behavior; this could include, for example, experiments employing a broader range of slip rates or an investigation of the effects of the compaction rate of coal exposed to different pore fluids.

We also note, from our previous direct shear experiments performed on simulated coal-shale fault gouges under similar PT conditions (see Liu et al., 2020), that the 50:50 volume fraction coal-shale mixtures exhibited a tendency for a transition from velocity weakening to velocity strengthening at a sliding velocity of $\sim 10 \mu \mathrm{ms}^{-1}$, as opposed to the pure coal samples reported here. This strongly suggests that the presence of mineral phases may play a significant role in the rate dependence of friction of coal-rich faults.

\subsection{Implications for the frictional strength and seismic potential of coal-rich faults}

Our experiments demonstrate that bituminous coal exhibits significant slip weakening at an initial displacement of $\sim 1-$ $2 \mathrm{~mm}$, when a sliding velocity of $1 \mu \mathrm{m} \mathrm{s}^{-1}$ is imposed under both dry and wet conditions, at a temperature of $100{ }^{\circ} \mathrm{C}$ and effective normal stress of $25-45 \mathrm{MPa}$. Posttest analysis suggests this marked slip weakening was caused by the development of strain localization in shear bands, accompanied by the improvement of the organization of molecular structure and accordingly of coal maturity. Similar slipweakening behavior associated with coal-rich shear bands was also observed on simulated coal-shale gouges with coal content $\geq 50$ vol $\%$ under similar PT conditions at sliding velocities of $0.1-100 \mu^{-1}$ siu et al., 2020). This suggests that this marked slip weakening of coal may play a role in promoting unstable slip of coal or coal-rich faults, i.e., facilitating accelerating fault slip and earthquake nucleation in coal-rich fault segments given appropriately low stiffness of the surrounding rock volume. However, the shear-unload-reshear experiments performed by Liu et al. (2020) on $50: 50$ volume fraction coal-shale mixtures suggest that significant slip weakening occurs only in previously unsheared material in which coal-rich shear bands have yet to develop (Logan et al., 1992; Marone, 1998). This suggests that slip weakening may not be prone to occur on coal-rich faults at the low slip velocities associated with rupture nucleation, as previous tectonic displacements potentially exceeded the $1-2 \mathrm{~mm}$ slip-weakening distance observed in our experiments. This is highly uncertain, however, since diagenetic processes in faults during periods of no slip may rework the gouge fabric so that renewed slip weakening may occur upon reactivation. Alternatively, marked slip weakening may occur in coal seams when new fractures are produced upon failure of the intact material caused by underground coal mining or (enhanced) coal-bed methane recovery operations. In addition, frictional slip of the coal-rock interface may also play an important role in the stability of coal-bearing faults (Wang et al., 2014; W. Li et al., 2015). On the other hand, our SHS experiment shows minor healing (restrengthening) effects of bituminous coal, with transient peak healing in friction increases with the logarithm of hold time (s) at a linearized rate of only $\sim 0.006$. This healing rate would become even smaller when adding $50 \mathrm{vol} \%$ shale (see Liu et al., 2020). Post-healing slip-weakening effects are correspondingly minor compared with healing rates typically measured in quartz or carbonate gouges (Nakatani and Scholz, 2004; Chen et al., 2015). We accordingly expect a minor effect of healing on the frictional strength of coal-coal or coal-rich faults, even after geological periods of healing, which again points to very limited scope for slip weakening and seismogenic rupture nucleation in the case of fault reactivation. Besides slip-weakening effects, we note that the near-steady-state frictional strength of coal yields $\sim 0.3$, which is insensitive to pore fluids and the effective normal stresses employed in this study. This suggests that the mechanical heterogeneity caused by weak coal-coal and coal-smear patches may also play a role in promoting the instability of faults (Tembe et al., 2010; Kohli and Zoback, 2013; Buijze et al., 2017; Kaneki and Hirono, 2019).

Our VS experiments demonstrate a transition from velocity strengthening to velocity weakening at a slip rate of $\sim$ $10 \mu \mathrm{m} \mathrm{s}^{-1}$ for wet coal at $15 \mathrm{MPa}$ pore water pressure, while this occurs at $\sim 1 \mu \mathrm{m} \mathrm{s}^{-1}$ for vacuum-dry coal. We inferred that this transition was caused by competition between dilatant granular flow and compaction by stress-strain-sorption behavior of coal. We note that this rate-dependent friction of coal, observed at slow slip velocities, may be changed by adding other minerals (e.g., coal-shale mixtures reported by Liu et al., 2020), as the dilatation and compaction processes and, accordingly, their competition will be changed. Therefore, whether coal-coal or smeared-out coal-rich fault patches exhibit velocity-weakening behavior and potentially cause seismogenic rupture nucleation (Scholz, 2019) remains an open question for a given fault.

\section{Conclusions}

This paper has investigated the frictional properties of simulated bituminous coal gouges under (nearly) in situ conditions of $100^{\circ} \mathrm{C}$ and $25-45 \mathrm{MPa}$ effective normal stresses, employing sliding velocities of $0.1-100 \mu \mathrm{m} \mathrm{s}^{-1}$. We determined the rate dependence of friction following RSF theory. Also, 
the frictional healing effect of coal was investigated by performing a single slide-hold-slide experiment with hold durations in the range 300 to $30000 \mathrm{~s}$. The microstructures of the deformed gouges were investigated, and the development of the molecular structure of coal was analyzed using XRD and Raman spectroscopy. The likely mechanisms controlling the frictional behavior were then discussed. The main findings are summarized as follows.

1. All simulated coal gouges showed marked slipweakening behavior, from a peak friction coefficient approaching $\sim 0.5$ to a near-steady-state value around only $\sim 0.3$, regardless of the applied effective normal stress $(25-45 \mathrm{MPa})$ or the presence of water (at $15 \mathrm{MPa}$ pore pressure) versus vacuum-dry conditions.

2. Microstructural observations, performed on the sheared samples using optical microscopy and an SEM, showed that all coal gouges developed a principal boundary slip zone with a marked stacked-layer structure and a weakly deformed zone. A single sample (S5) showed clear R- and Y-shear bands. This suggests strain localization in the shear bands of a coal gouge.

3. The crystal structure of the coal samples was investigated using XRD. Our results showed that (a) no graphite was formed due to the shear-friction processes; and (b) following shear deformation, the interlayer spacing of graphite-like structure $\left(d_{002}\right)$ decreased from $\sim 3.57$ to 3.47-3.53, while the stacked height $\left(L_{\mathrm{c}}\right)$ and aromaticity $\left(f_{\mathrm{a}}\right)$ increased from $\sim 13$ to $\sim 20 \AA$ and from $0.44-0.49$ to $0.53-0.67$, respectively. This suggests an improvement in the crystallinity of the sheared coal samples, which may be caused by strain localization associated with strain energy developed in the shear bands.

4. Raman spectroscopy showed that (a) D and G bands were present in all samples at $\sim 1360$ and $\sim 1600 \mathrm{~cm}^{-1}$, respectively; (b) both $\mathrm{D}$ and $\mathrm{G}$ bands observed in the sheared samples are more narrow than those observed in the unsheared samples; and (c) G-FWHM values decreased from 91.3 to $71.7-79.7 \mathrm{~cm}^{-1}$ following shear deformation, while RBS and SI values increased from 227.7 to $239.3-256.7 \mathrm{~cm}^{-1}$ and from 3.27 to $3.65-4.26$, respectively. This all indicates an increase in coal maturity, which is in good agreement with our XRD results.

5. Based on the above findings (2-4), we suggest that the marked slip-weakening behavior of coal could largely be attributed to the development of R-, B- and Y-shear bands, i.e., strain localization in shear bands, accompanied by the improvement of the crystallinity and maturity of coal.

6. From an RSF point of view, our VS experiments showed a transition from velocity strengthening to velocity weakening at a slip velocity of $\sim 1 \mu \mathrm{ms}^{-1}$ in the coal sample under vacuum-dry conditions but at $\sim 10 \mu \mathrm{ms}^{-1}$ in coal samples exposed to DI water at $15 \mathrm{MPa}$ pore pressure. This may be dominated by competition between dilatant granular flow and compaction enhanced by the presence of water.

7. The single SHS experiment revealed transient peak healing (restrengthening), which increased log-linearly with hold time at a rate of $\sim 0.006$, demonstrating minor time-dependent healing.

8. Our findings, together with our previous research on the frictional properties of coal-shale mixtures, suggest that the rather marked slip weakening of coal may not be prone to occur on preexisting coal-rich faults with a well-developed, localized internal structure, at least for low slip velocities associated with rupture nucleation; it may occur in coal seams when failure or new fractures are produced by underground coal mining or (enhanced) coal-bed methane recovery. Such behavior may lead to accelerating slip and the associated possible seismic hazard. Based on our single SHS experiment, healing is expected to play only a minor role in the frictional strength evolution of coal-rich faults, even for geological timescales, which again points to very limited scope for slip weakening and seismogenic rupture nucleation in the case of fault reactivation. The rate dependence of friction observed in coal gouges may change due to the addition of other minerals (e.g., coal-shale mixtures), which suggests that the seismogenic potential of coalbearing faults via velocity-weakening behavior remains an open question for a given fault.

Data availability. The landing page for all original data is https:// public.yoda.uu.nl/geo/UU01/48I5DA.html (last access: July 2020), alongside https://doi.org/10.24416/UU01-48I5DA (Liu and Hunfeld, 2020).

Author contributions. Investigation and research were performed by all of the authors. Specifically, CF performed XRD and Raman experiments, processed all data, and wrote the original draft under the supervision of JL; JL, with the help of $\mathrm{LBH}$, performed friction experiments and produced metadata; JL and CJS formulated the ideas and research goals of this paper; JL, LBH and CJS conducted a critical review and revisions.

Competing interests. The authors declare that they have no conflict of interest.

Special issue statement. This article is part of the special issue "Thermo-hydro-mechanical-chemical (THMC) processes in natural and induced seismicity". It is a result of the The 7th International 
Conference on Coupled THMC Processes, Utrecht, Netherlands, 35 July 2019.

Acknowledgements. The National Natural Science Foundation of China is acknowledged for their financial support. Jianye Chen is thanked for discussions, and HPT lab technicians Gert Kastelein and Floris van Oort are thanked for their superb technical support. Luuk B. Hunfeld and part of the experimental work conducted at Utrecht were supported through the research program on induced seismicity in the Groningen Gas Field funded by the field operator, the Nederlandse Aardolie Maatschappij (NAM).

Financial support. This research has been supported by the National Natural Science Foundation of China (project no. 41802230) and the Nederlandse Aardolie Maatschappij.

Review statement. This paper was edited by Jianye Chen and reviewed by Oohashi Kiyokazu and one anonymous referee.

\section{References}

Ahamed, M. A. A., Perera, M. S. A., Matthai, S. K., Ranjith, P. G., and Dong-yin, L.: Coal composition and structural variation with rank and its influence on the coalmoisture interactions under coal seam temperature conditions - A review article, J. Petrol. Sci. Eng., 180, 901-917, https://doi.org/10.1016/j.petrol.2019.06.007, 2019.

Aharonov, E. and Scholz, C. H.: A Physics-Based Rock Friction Constitutive Law: Steady State Friction, J. Geophys. Res.-Sol. Ea., 123, 1591-1614, https://doi.org/10.1002/2016JB013829, 2018.

Baysal, M., Yürüm, A., Yıldız, B., and Yürüm, Y.: Structure of some western Anatolia coals investigated by FTIR, Raman, ${ }^{13} \mathrm{C}$ solid state NMR spectroscopy and X-ray diffraction, Int. J. Coal Geol., 163, 166-176, https://doi.org/10.1016/j.coal.2016.07.009, 2016.

Beyssac, O., Rouzaud, J.-N., Goffé, B., Brunet, F., and Chopin, C.: Graphitization in a high-pressure, low-temperature metamorphic gradient: a Raman microspectroscopy and HRTEM study, Contrib. Mineral. Petr., 143, 19-31, https://doi.org/10.1007/s00410001-0324-7, 2002.

Beyssac, O., Goffé, B., Petitet, J.-P., Froigneux, E., Moreau, M., and Rouzaud, J.-N.: On the characterization of disordered and heterogeneous carbonaceous materials by Raman spectroscopy, Spectrochim. Acta A, 59, 2267-2276, https://doi.org/10.1016/S13861425(03)00070-2, 2003.

Blanpied, M. L., Tullis, T. E., and Weeks, J. D.: Effects of slip, slip rate, and shear heating on the friction of granite, J. Geophys. Res.-Sol. Ea., 103, 489-511, https://doi.org/10.1029/97JB02480, 1998.

Bonijoly, M., Oberlin, M., and Oberlin, A.: A possible mechanism for natural graphite formation, Int. J. Coal Geol., 1, 283-312, https://doi.org/10.1016/0166-5162(82)90018-0, 1982.
Brace, W. F. and Byerlee, J. D.: Stick-Slip as a Mechanism for Earthquakes, Science, 153, 990-992, https://doi.org/10.1126/science.153.3739.990, 1966.

Buijze, L., van den Bogert, P. A. J., Wassing, B. B. T., Orlic, B., and ten Veen, J.: Fault reactivation mechanisms and dynamic rupture modelling of depletion-induced seismic events in a Rotliegend gas reservoir, Neth. J. Geosci., 96, s131-s148, https://doi.org/10.1017/njg.2017.27, 2017.

Buseck, P. R. and Beyssac, O.: From Organic Matter to Graphite: Graphitization, Elements, 10, 421-426, https://doi.org/10.2113/gselements.10.6.421, 2014.

Buseck, P. R. and Huang, B.-J.: Conversion of carbonaceous material to graphite during metamorphism, Geochim. Cosmochim. Ac., 49, 2003-2016, https://doi.org/10.1016/00167037(85)90059-6, 1985.

Bustin, R. M., Ross, J. V., and Rouzaud, J.-N.: Mechanisms of graphite formation from kerogen: experimental evidence, Int. J. Coal Geol., 28, 1-36, https://doi.org/10.1016/01665162(95)00002-U, 1995a.

Bustin, R. M., Rouzaud, J.-N., and Ross, J. V.: Natural graphitization of anthracite: Experimental considerations, Carbon, 33, 679-691, https://doi.org/10.1016/0008-6223(94)00155S, 1995b.

Cao, D., Li, X., and Zhang, S.: Influence of tectonic stress on coalification: Stress degradation mechanism and stress polycondensation mechanism, Sci. China, Ser. D, 50, 43-54, https://doi.org/10.1007/s11430-007-2023-3, 2007.

Chen, J. and Spiers, C. J.: Rate and state frictional and healing behavior of carbonate fault gouge explained using microphysical model: Microphysical Model for Friction, J. Geophys. Res.-Sol. Ea., 121, 8642-8665, https://doi.org/10.1002/2016JB013470, 2016.

Chen, J., Verberne, B. A., and Spiers, C. J.: Effects of healing on the seismogenic potential of carbonate fault rocks: Experiments on samples from the Longmenshan Fault, Sichuan, China, J. Geophys. Res.-Sol. Ea., 120, 5479-5506, https://doi.org/10.1002/2015JB012051, 2015.

Chen, S., Yin, D., Jiang, N., Wang, F., and Zhao, Z.: Mechanical properties of oil shale-coal composite samples, Int. J. Rock Mech. Min., 123, 104120, https://doi.org/10.1016/j.ijrmms.2019.104120, 2019.

Childres, I., Jauregui, L. A., Park, W., Cao, H., and Chen, Y. P.: Raman spectroscopy of graphene and related materials, in: New Developments in Photon and Materials Research, 403-418, Nova Science Publishers, Inc., 2013.

Dieterich, J. H.: Modeling of rock friction: 1. Experimental results and constitutive equations, J. Geophys. Res., 84, 2161, https://doi.org/10.1029/JB084iB05p02161, 1979.

Di Toro, G., Han, R., Hirose, T., De Paola, N., Nielsen, S., Mizoguchi, K., Ferri, F., Cocco, M., and Shimamoto, T.: Fault lubrication during earthquakes, Nature, 471, 494-498, https://doi.org/10.1038/nature09838, 2011.

Dun, W., Guijian, L., Ruoyu, S., and Xiang, F.: Investigation of structural characteristics of thermally metamorphosed coal by FTIR spectroscopy and X-ray diffraction, Energy Fuels, 27, 5823-5830, https://doi.org/10.1021/ef401276h, 2013.

Ellsworth, W. L.: Injection-Induced Earthquakes, Science, 341, 142, https://doi.org/10.1126/science.1225942, 2013. 
Fan, L. and Liu, S.: Fluid-dependent shear slip behaviors of coal fractures and their implications on fracture frictional strength reduction and permeability evolutions, Int. J. Coal Geol., 212, 103235, https://doi.org/10.1016/j.coal.2019.103235, 2019.

Faulkner, D. R., Sanchez-Roa, C., Boulton, C., and den Hartog, S. A. M.: Pore Fluid Pressure Development in Compacting Fault Gouge in Theory, Experiments, and Nature, J. Geophys. Res.Sol. Ea., 123, 226-241, https://doi.org/10.1002/2017JB015130, 2018.

Fondriest, M., Smith, S. A. F., Candela, T., Nielsen, S. B., Mair, K., and Toro, G. D.: Mirror-like faults and power dissipation during earthquakes, Geology, 41, 1175-1178, https://doi.org/10.1130/G34641.1, 2013.

Guo, W.-Y., Tan, Y.-L., Yu, F.-H., Zhao, T.-B., Hu, S.-C., Huang, D.-M., and Qin, Z.: Mechanical behavior of rock-coal-rock specimens with different coal thicknesses, Geomech. Eng., 15, 10171027, https://doi.org/10.12989/GAE.2018.15.4.1017, 2018.

Hadizadeh, J., Tullis, T. E., White, J. C., and Konkachbaev, A. I.: Shear localization, velocity weakening behavior, and development of cataclastic foliation in experimental granite gouge, J. Struct. Geol., 71, 86-99, https://doi.org/10.1016/j.jsg.2014.10.013, 2015.

Henry, D. G., Jarvis, I., Gillmore, G., Stephenson, M., and Emmings, J. F.: Assessing low-maturity organic matter in shales using Raman spectroscopy: Effects of sample preparation and operating procedure, Int. J. Coal Geol., 191, 135-151, https://doi.org/10.1016/j.coal.2018.03.005, 2018.

Henry, D. G., Jarvis, I., Gillmore, G., and Stephenson, M.: A rapid method for determining organic matter maturity using Raman spectroscopy: Application to Carboniferous organicrich mudstones and coals, Int. J. Coal Geol., 203, 87-98, https://doi.org/10.1016/j.coal.2019.01.003, 2019.

Hirsch, P.: X-ray scattering from coals, Proc. R. Soc. A, 226, 143169, https://doi.org/10.1098/rspa.1954.0245, 1954.

Hol, S., Peach, C. J., and Spiers, C. J.: Applied stress reduces the $\mathrm{CO}_{2}$ sorption capacity of coal, Int. J. Coal Geol., 85, 128-142, https://doi.org/10.1016/j.coal.2010.10.010, 2011.

Hou, Q., Luo, Y., Han, Y., Du, J., and Xu, R.: Gas generation during middle-rank coal deformation and the reliminary discussion ofthe mechanism, J. China Coal Soc., 39, 1678-1682, 2014 (in Chinese).

Hou, Q., Han, Y., Wang, J., Dong, Y., and Pan, J.: The impacts of stress on the chemical structure of coals: a mini-review based on the recent development of mechanochemistry, Sci. Bull., 62, 965-970, https://doi.org/10.1016/j.scib.2017.06.004, 2017.

Hunfeld, L. B., Niemeijer, A. R., and Spiers, C. J.: Frictional Properties of Simulated Fault Gouges from the Seismogenic Groningen Gas Field Under In Situ P-T Chemical Conditions: Friction of Groningen fault gouges, J. Geophys. Res.-Sol. Ea., 122, 89698989, https://doi.org/10.1002/2017JB014876, 2017.

Ikari, M. J., Saffer, D. M., and Marone, C.: Frictional and hydrologic properties of a major splay fault system, Nankai subduction zone, Geophys. Res. Lett., 36, L20313, https://doi.org/10.1029/2009GL040009, 2009.

Ikari, M. J., Marone, C., Saffer, D. M., and Kopf, A. J.: Slip weakening as a mechanism for slow earthquakes, Nat. Geosci., 6, 468472, https://doi.org/10.1038/ngeo1818, 2013.

Jiang, J., Yang, W., Cheng, Y., Liu, Z., Zhang, Q., and Zhao, K.: Molecular structure characterization of middle- high rank coal via XRD, Raman and FTIR spectroscopy: Implications for coalification, Fuel, 239, 559-572, https://doi.org/10.1016/j.fuel.2018.11.057, 2019.

Ju, Y., Jiang, B., Hou, Q., and Wang, G.: Relationship between nanoscale deformation of coal structure and metamorphicdeformed environments, Chinese Sci. Bull., 50, 1785-1796, https://doi.org/10.1360/04wd0205, 2005.

Kaneki, S. and Hirono, T.: Diagenetic and shear-induced transitions of frictional strength of carbon-bearing faults and their implications for earthquake rupture dynamics in subduction zones, Sci. Rep.-UK, 9, 7884, https://doi.org/10.1038/s41598-019-44307-y, 2019.

Kaneki, S., Ichiba, T., and Hirono, T.: Mechanochemical Effect on Maturation of Carbonaceous Material: Implications for Thermal Maturity as a Proxy for Temperature in Estimation of Coseismic Slip Parameters, Geophys. Res. Lett., 45, 2248-2256, https://doi.org/10.1002/2017GL076791, 2018.

Khatibi, S., Ostadhassan, M., Tuschel, D., Gentzis, T., Bubach, B., and Carvajal-Ortiz, H.: Raman spectroscopy to study thermal maturity and elastic modulus of kerogen, Int. J. Coal Geol., 185, 103-118, https://doi.org/10.1016/j.coal.2017.11.008, 2018.

Kirilova, M., Toy, V. G., Timms, N., Halfpenny, A., Menzies, C., Craw, D., Beyssac, O., Sutherland, R., Townend, J., Boulton, C., Carpenter, B. M., Cooper, A., Grieve, J., Little, T., Morales, L., Morgan, C., Mori, H., Sauer, K. M., Schleicher, A. M., Williams, J., and Craw, L.: Textural changes of graphitic carbon by tectonic and hydrothermal processes in an active plate boundary fault zone, Alpine Fault, New Zealand, Geol. Soc. Lond. Spec. Publ., 453, 205-223, https://doi.org/10.1144/SP453.13, 2017.

Kirilova, M., Toy, V., Rooney, J. S., Giorgetti, C., Gordon, K. C., Collettini, C., and Takeshita, T.: Structural disorder of graphite and implications for graphite thermometry, Solid Earth, 9, 223231, https://doi.org/10.5194/se-9-223-2018, 2018.

Kitamura, M., Mukoyoshi, H., Fulton, P. M., and Hirose, T.: Coal maturation by frictional heat during rapid fault slip, Geophys. Res. Lett., 39, https://doi.org/10.1029/2012GL052316, 2012.

Kohli, A. H. and Zoback, M. D.: Frictional properties of shale reservoir rocks, J. Geophys. Res.-Sol. Ea., 118, 5109-5125, https://doi.org/10.1002/jgrb.50346, 2013.

Kuo, L.-W., Li, H., Smith, S. A. F., Di Toro, G., Suppe, J., Song, S.-R., Nielsen, S., Sheu, H.-S., and Si, J.: Gouge graphitization and dynamic fault weakening during the $2008 M_{\mathrm{W}} 7.9$ Wenchuan earthquake, Geology, 42, 47-50, https://doi.org/10.1130/G34862.1, 2014.

Kuo, L.-W., Huang, J.-R., Fang, J.-N., Si, J., Song, S.-R., Li, H., and Yeh, E.-C.: Carbonaceous Materials in the Fault Zone of the Longmenshan Fault Belt: 2. Characterization of Fault Gouge from Deep Drilling and Implications for Fault Maturity, Minerals, 8, 393, https://doi.org/10.3390/min8090393, 2018.

Li, K., Khanna, R., Zhang, J., Barati, M., Liu, Z., Xu, T., Yang, T., and Sahajwalla, V.: Comprehensive Investigation of Various Structural Features of Bituminous Coals Using Advanced Analytical Techniques, Energy Fuels, 29, 7178-7189, https://doi.org/10.1021/acs.energyfuels.5b02064, 2015.

Li, W., Bai, J., Cheng, J., Peng, S., and Liu, H.: Determination of coal-rock interface strength by laboratory direct shear tests under constant normal load, Int. J. Rock Mech. Min., 77, 60-67, https://doi.org/10.1016/j.ijrmms.2015.03.033, 2015. 
Li, Z., Wei, X.-Y., Yan, H.-L., and Zong, Z.-M.: Insight into the structural features of Zhaotong lignite using multiple techniques, Fuel, 153, 176-182, https://doi.org/10.1016/j.fuel.2015.02.117, 2015.

Liu, J. and Hunfeld, L. B.: Frictional slip weakening and shearenhanced crystallinity in simulated coal fault gouges at subseismic slip rates, EPOS repository, https://doi.org/10.24416/UU0148I5DA, 2020.

Liu, J., Spiers, C. J., Peach, C. J., and Vidal-Gilbert, S.: Effect of lithostatic stress on methane sorption by coal: Theory vs. experiment and implications for predicting in-situ coalbed methane content, Int. J. Coal Geol., 167, 48-64, https://doi.org/10.1016/j.coal.2016.07.012, 2016.

Liu, J., Fokker, P. A., Peach, C. J., and Spiers, C. J.: Applied stress reduces swelling of coal induced by adsorption of water, Geomechanics for Energy and the Environment, 16, 45-63, https://doi.org/10.1016/j.gete.2018.05.002, 2018.

Liu, J., Hunfeld, L. B., Niemeijer, A. R., and Spiers, C. J.: Frictional properties of simulated shale-coal fault gouges: Implications for induced seismicity in source rocks below Europe's largest gas field, Int. J. Coal Geol., 226, 103499, https://doi.org/10.1016/j.coal.2020.103499, 2020.

Logan, J. M., Dengo, C. A., Higgs, N. G., and Wang, Z. Z.: Fabrics of Experimental Fault Zones: Their Development and Relationship to Mechanical Behavior, Int. Geophys., 51, 33-67, https://doi.org/10.1016/S0074-6142(08)62814-4, 1992.

Lu, L., Sahajwalla, V., Kong, C., and Harris, D.: Quantitative X-ray diffraction analysis and its application to various coals, Carbon, 39, 1821-1833, https://doi.org/10.1016/S0008-6223(00)003183, 2001 .

Ma, T.-B., Wang, L.-F., Hu, Y.-Z., Li, X., and Wang, H.: A shear localization mechanism for lubricity of amorphous carbon materials, Sci. Rep.-UK, 4, 3662, https://doi.org/10.1038/srep03662, 2014

Marone, C.: Laboratory-derived Friction Laws and their Application to Seismic Faulting, Annu. Rev. Earth Pl. Sc., 26, 643-696, https://doi.org/10.1146/annurev.earth.26.1.643, 1998.

Mathews, J. P. and Chaffee, A. L.: The molecular representations of coal - A review, Fuel, 96, 1-14, https://doi.org/10.1016/j.fuel.2011.11.025, 2012.

Moore, D. E. and Lockner, D. A.: Crystallographic controls on the frictional behavior of dry and water-saturated sheet structure minerals, J. Geophys. Res.-Sol. Ea., 109, B03401, https://doi.org/10.1029/2003JB002582, 2004.

Morrow, C. A., Moore, D. E., and Lockner, D. A.: The effect of mineral bond strength and adsorbed water on fault gouge frictional strength, Geophys. Res. Lett., 27, 815-818, https://doi.org/10.1029/1999GL008401, 2000.

Nakamura, Y., Oohashi, K., Toyoshima, T., Satish-Kumar, M., and Akai, J.: Strain-induced amorphization of graphite in fault zones of the Hidaka metamorphic belt, Hokkaido, Japan, J. Struct. Geol., 72, 142-161, https://doi.org/10.1016/j.jsg.2014.10.012, 2015.

Nakatani, M. and Scholz, C. H.: Frictional healing of quartz gouge under hydrothermal conditions: 1. Experimental evidence for solution transfer healing mechanism, J. Geophys. Res.-Sol. Ea. 109, B07201, https://doi.org/10.1029/2001JB001522, 2004.

Niemeijer, A. R. and Spiers, C. J.: A microphysical model for strong velocity weakening in phyllosilicate- bearing fault gouges, J. Geophys. Res., 112, B10405, https://doi.org/10.1029/2007JB005008, 2007.

Niu, Z., Liu, G., Yin, H., Wu, D., and Zhou, C.: Investigation of mechanism and kinetics of non-isothermal low temperature pyrolysis of perhydrous bituminous coal by in-situ FTIR, Fuel, 172, 1-10, https://doi.org/10.1016/j.fuel.2016.01.007, 2016.

Oberlin, A.: Carbonization and graphitization, Carbon, 22, 521541, https://doi.org/10.1016/0008-6223(84)90086-1, 1984.

O'Hara, K., Mizoguchi, K., Shimamoto, T., and Hower, J. C.: Experimental frictional heating of coal gouge at seismic slip rates: Evidence for devolatilization and thermal pressurization of gouge fluids, Tectonophysics, 424, 109-118, https://doi.org/10.1016/j.tecto.2006.07.007, 2006.

Okolo, G. N., Neomagus, H. W. J. P., Everson, R. C., Roberts, M. J., Bunt, J. R., Sakurovs, R., and Mathews, J. P.: Chemicalstructural properties of South African bituminous coals: Insights from wide angle XRD-carbon fraction analysis, ATR-FTIR, solid state ${ }^{13} \mathrm{C}$ NMR, and HRTEM techniques, Fuel, 158, 779792, https://doi.org/10.1016/j.fuel.2015.06.027, 2015.

Oohashi, K., Hirose, T., and Shimamoto, T.: Shear-induced graphitization of carbonaceous materials during seismic fault motion: Experiments and possible implications for fault mechanics, J. Struct. Geol., 33, 1122-1134, https://doi.org/10.1016/j.jsg.2011.01.007, 2011.

Oohashi, K., Hirose, T., Kobayashi, K., and Shimamoto, T.: The occurrence of graphite-bearing fault rocks in the 4 fault system, Japan: Origins and implications for fault creep, J. Struct. Geol., 38, 39-50, https://doi.org/10.1016/j.jsg.2011.10.011, 2012.

Oohashi, K., Hirose, T., and Shimamoto, T.: Graphite as a lubricating agent in fault zones: An insight from lowto high-velocity friction experiments on a mixed graphitequartz gouge, J. Geophys. Res.-Sol. Ea., 118, 2067-2084, https://doi.org/10.1002/jgrb.50175, 2013.

Öztaş, N. A. and Yürüm, Y.: Pyrolysis of Turkish Zonguldak bituminous coal. Part 1. Effect of mineral matter, Fuel, 79, 12211227, https://doi.org/10.1016/S0016-2361(99)00255-0, 2000.

Pan, J., Lv, M., Bai, H., Hou, Q., Li, M., and Wang, Z.: Effects of Metamorphism and Deformation on the Coal Macromolecular Structure by Laser Raman Spectroscopy, Energy Fuels, 31, 1136-1146, https://doi.org/10.1021/acs.energyfuels.6b02176, 2017.

Potgieter-Vermaak, S., Maledi, N., Wagner, N., Van Heerden, J. H. P., Van Grieken, R., and Potgieter, J. H.: Raman spectroscopy for the analysis of coal: a review, J. Raman Spectrosc., 42, 123-129, https://doi.org/10.1002/jrs.2636, 2011.

Rice, J. R.: Heating and weakening of faults during earthquake slip, J. Geophys. Res.-Sol. Ea., 111, B05311, https://doi.org/10.1029/2005JB004006, 2006.

Ross, J. V. and Bustin, R. M.: The role of strain energy in creep graphitization of anthracite, Nature, 343, 58-60, https://doi.org/10.1038/343058a0, 1990.

Ross, J. V., Bustin, R. M., and Rouzaud, J. N.: Graphitization of high rank coals - the role of shear strain: experimental considerations, Org. Geochem., 17, 585-596, https://doi.org/10.1016/0146-6380(91)90002-2, 1991.

Ruan, J. and Bhushan, B.: Frictional behavior of highly oriented pyrolytic graphite, J. Appl. Phys., 76, 8117-8120, https://doi.org/10.1063/1.357861, 1994. 
Ruina, A.: Slip instability and state variable friction laws, J. Geophys. Res.-Sol. Ea., 88, 10359-10370, https://doi.org/10.1029/JB088iB12p10359, 1983.

Rutter, E. H., Hackston, A. J., Yeatman, E., Brodie, K. H., Mecklenburgh, J., and May, S. E.: Reduction of friction on geological faults by weak-phase smearing, J. Struct. Geol., 51, 52-60, https://doi.org/10.1016/j.jsg.2013.03.008, 2013.

Sadezky, A., Muckenhuber, H., Grothe, H., Niessner, R., and Pöschl, U.: Raman microspectroscopy of soot and related carbonaceous materials: Spectral analysis and structural information, Carbon, 43, 1731-1742, https://doi.org/10.1016/j.carbon.2005.02.018, 2005.

Samuelson, J. and Spiers, C. J.: Fault friction and slip stability not affected by $\mathrm{CO}_{2}$ storage: Evidence from shortterm laboratory experiments on North Sea reservoir sandstones and caprocks, Int. J. Greenh. Gas Con., 11, S78-S90, https://doi.org/10.1016/j.ijggc.2012.09.018, 2012.

Schito, A., Romano, C., Corrado, S., Grigo, D., and Poe, B.: Diagenetic thermal evolution of organic matter by Raman spectroscopy, Org. Geochem., 106, 57-67, https://doi.org/10.1016/j.orggeochem.2016.12.006, 2017.

Scholz, C. H.: Earthquakes and friction laws, Nature, 391, 37-42, https://doi.org/10.1038/34097, 1998.

Scholz, C. H.: The Mechanics of Earthquakes and Faulting, 3rd Edn., Cambridge University Press, https://doi.org/10.1017/9781316681473, 2019.

Siman-Tov, S., Aharonov, E., Sagy, A., and Emmanuel, S.: Nanograins form carbonate fault mirrors, Geology, 41, 703-706, https://doi.org/10.1130/G34087.1, 2013.

Song, Y., Jiang, B., and Han, Y.: Macromolecular response to tectonic deformation in low-rank tectonically deformed coals (TDCs), Fuel, 219, 279-287, https://doi.org/10.1016/j.fuel.2018.01.133, 2018.

Song, Y., Jiang, B., and Qu, M.: Macromolecular evolution and structural defects in tectonically deformed coals, Fuel, 236, 1432-1445, https://doi.org/10.1016/j.fuel.2018.09.080, 2019.

Tembe, S., Lockner, D. A., and Wong, T.-F.: Effect of clay content and mineralogy on frictional sliding behavior of simulated gouges: Binary and ternary mixtures of quartz, illite, and montmorillonite, J. Geophys. Res.-Sol. Ea., 115, B03416, https://doi.org/10.1029/2009JB006383, 2010.

Tuinstra, F. and Koenig, J. L.: Raman spectrum of graphite, J. Chem. Phys., 53, 1126-30, https://doi.org/10.1063/1.1674108, 1970.

Ulyanova, E. V., Molchanov, A. N., Prokhorov, I. Y., and Grinyov, V. G.: Fine structure of Raman spectra in coals of different rank, Int. J. Coal Geol., 121, 37-43, https://doi.org/10.1016/j.coal.2013.10.014, 2014.
Verberne, B. A., Spiers, C. J., Niemeijer, A. R., De Bresser, J. H. P., De Winter, D. A. M., and Plümper, O.: Frictional Properties and Microstructure of Calcite-Rich Fault Gouges Sheared at Sub-Seismic Sliding Velocities, Pure Appl. Geophys., 171, 2617-2640, https://doi.org/10.1007/s00024-013-0760-0, 2014a.

Verberne, B. A., Plumper, O., de Winter, D. A. M., and Spiers, C. J.: Superplastic nanofibrous slip zones control seismogenic fault friction, Science, 346, 1342-1344, https://doi.org/10.1126/science.1259003, 2014b.

Wang, L., Cao, D., Peng, Y., Ding, Z., and Li, Y.: Straininduced graphitization mechanism of coal-based graphite from lutang, hunan province, china, Minerals, 9, 617, https://doi.org/10.3390/min9100617, 2019.

Wang, T., Jiang, Y., Zhan, S., and Wang, C.: Frictional sliding tests on combined coal-rock samples, Journal of Rock Mechanics and Geotechnical Engineering, 6, 280-286, https://doi.org/10.1016/j.jrmge.2014.03.007, 2014.

Westbrook, G. K., Kusznir, N. J., Browitt, C. W. A., and Holdsworth, B. K.: Seismicity induced by coal mining in Stoke-on-Trent (U.K.), Eng. Geol., 16, 225-241, https://doi.org/10.1016/0013-7952(80)90017-4, 1980.

Wilkins, R. W. T., Boudou, R., Sherwood, N., and Xiao, X.: Thermal maturity evaluation from inertinites by Raman spectroscopy: The "RaMM" technique, Int. J. Coal Geol., 128-129, 143-152, https://doi.org/10.1016/j.coal.2014.03.006, 2014.

Wilks, K. R., Mastalerz, M., Bustin, R. M., and Ross, J. V.: The role of shear strain in the graphitization of a high-volatile bituminous and an anthracitic coal, Int. J. Coal Geol., 22, 247-277, https://doi.org/10.1016/0166-5162(93)90029-A, 1993.

$\mathrm{Xu}, \mathrm{R} ., \mathrm{Li}, \mathrm{H} ., \mathrm{Guo}, \mathrm{C}$., and Hou, Q.: The mechanisms of gas generation during coal deformation: Preliminary observations, Fuel, 117, 326-330, https://doi.org/10.1016/j.fuel.2013.09.035, 2014.

Yen, T. F., Erdman, J. G., and Pollack, S. S.: Investigation of the Structure of Petroleum Asphaltenes by X-Ray Diffraction, Anal. Chem., 33, 1587-1594, https://doi.org/10.1021/ac60179a039, 1961.

Zhang, W., Chen, S., Han, F., and Wu, D.: An experimental study on the evolution of aggregate structure in coals of different ranks by in situ X-ray diffractometry, Anal. Methods, 7, 8720-8726, https://doi.org/10.1039/C5AY01922B, 2015.

Zhang, Y. and Li, Z.: Raman spectroscopic study of chemical structure and thermal maturity of vitrinite from a suite of Australia coals, Fuel, 241, 188-198, https://doi.org/10.1016/j.fuel.2018.12.037, 2019.

Zhao, L., Guo, H., and Ma, Q.: Study on gaseous products distributions during coal pyrolysis, Coal Convers., 30, 5-9, 2007 (in Chinese). 